\title{
Fractal Urbanism: \\ City Size and Residential Segregation in India
}

\author{
Naveen Bharathi \\ Harvard University \\ naveenbharathi@fas.harvard.edu
}

\author{
Deepak Malghan \\ Indian Institute of \\ Management Bangalore
}

dmalghan@iimb.ac.in
Sumit Mishra

Krea University

sumit.mishra@krea.edu.in
Andaleeb Rahman

Cornell University

ar687@cornell.edu

We present the first ever large-scale snapshot of urban residential segregation in India at the neighborhood-scale. Our analysis from 147 largest cities in contemporary India shows how caste-based residential segregation is independent of city size (our sample includes all cities in India with at least 0.3 million residents in 2011). The extent of segregation in the largest metropolitan centers with over ten million residents closely tracks cities that are nearly two orders-of-magnitude smaller. We also show how residential segregation across a large swathe of urban India mirrors the spatial geometry of rural India. Our findings call into question one of the central normative promises of modernization in India and elsewhere --- the gradual withering of traditional ascriptive identities such as caste. Our paper also contributes to the emerging debates in urban segregation by developing an interdisciplinary framework for analytical and empirical operationalization of a neighborhood unit. 


\section{Introduction}

Cities are hailed as sites of economic, social, and even political transformation (Glaeser 2011; Mumford 1961). Yet, it is not clear how (if) urbanization modifies ascriptive identities that define social structures in an agrarian regime. In the case of India, it has long been assumed in both scholarship and praxis that larger and economically more vibrant cities are better able to transcend the hierarchical cleavages defined by hereditary institutions such as caste (Jodhka 2017; Kapur 2017; Qadeer 1974). However, there is considerable empirical evidence that institutions and practices associated with caste continue to persist in urban India (Mosse 2018, 2019). Constitutive elements of caste practice including untouchability, endogamous marriages, discrimination in housing and labor markets have been documented in India's largest metropolitan centers embedded in global economic networks (Banerjee and Knight 1985; Deshpande 2011; Thorat et al. 2015). While urbanization in India has transformed and even modulated some aspects of caste inequalities, caste has not structurally disappeared from urban India (Desai and Dubey 2011; Deshpande and Ramachandran 2019). Thus, the normative promise of India's urbanization dismantling social, political, and economic networks centered on exclusionary caste boundaries is best studied as a contingent hypothesis rather than as an article of faith.

In this paper, we investigate the impact of India's burgeoning urbanization on caste-based residential segregation. Residential segregation is an important driver, as well as the product of the "socio-spatial dialectic" (Soja 1980) which mediates the relationship between rapid urbanization and potential social transformation. We examine how (if) spatial organization in urban India differs from the segregated spaces of village India. Are large well-established, globally connected, and economically buoyant cities less or more segregated than fledgling smaller towns? Do urban growth rates determine patterns of residential segregation? Our analysis - that to the best of our knowledge represents the first large-scale neighborhood-resolution analysis of residential segregation in urban India - suggests that patterns of neighborhood segregation in India's largest metropolises with over ten million residents closely tracks much smaller towns that are not directly 
embedded in global cosmopolitan networks. Indeed, we find that the "geometry" (Simmel 2009) of urban residential segregation resembles historical division of space in the countryside.

Existing segregation studies in India have relied on aggregate ward-level data due to lack of data availability at more finer spatial scales (Bharathi, Malghan, and Rahman 2019; Sidhwani 2015; Singh, Vithayathil, and Pradhan 2019; Vithayathil and Singh 2012) even when it is the immediate neighborhood in which one grows up as a child that determines opportunities for mobility (Chetty, Hendren, and Katz 2016). Wards are the most elementary administrative and political units in urban India that can contain over 100,000 residents in large cities. While wards within a city are surely segregated, their large size renders them unsuitable as analytical approximations of a 'neighborhood,' consistent with residents' psychological perceptions. Residential segregation spans spatial scales - demographic composition of the wards is different from the city, and population group shares vary substantially between individual neighborhoods represented by streets, lanes, and alleys marked by artificial or natural borders, within a ward. Ethnographic evidence for such intraward segregation abound. For example, Tolas and Balmiki Nagars, the residential quarters of marginalized groups, are often perfectly segregated within wards that also contain upper class enclaves (Bharathi et al. 2019; Dupont 2004). Such multi-scale fractal segregation geometry is a result of "recombinant urbanization" processes (Balakrishnan 2019), that reproduce historical, social, and spatial configurations from the countryside in urban settings.

We study residential segregation across spatial scales (including at fine neighborhood resolution) across 147 largest cities in India. Our analysis that develops the first large-scale portrait of the relationship between multi-scale segregation and city size in the Global South uncovers a phenomenon that we term Fractal Urbanism. We also show that while urbanization in developing societies such as India might be driven by social and political processes that differ from the West, it is accompanied by residential segregation that is at least as acute. Thus, while it is indeed important to distinguish urban forms in late industrializing contexts, i.e. the Global South, from those that developed in the West (Bhan 2019; Ren 2018), it would be an error to study urbanization in places 
like India as a sui generis process. The robust empirical evidence for multi-scale segregation calls into question the widespread assumption that agrarian transformation brought about by industrialization, urbanization, and proliferation of transport and communications networks would weaken and ultimately break down institutions of ascription (Kapur 2017).

\section{Residential Segregation and Fractal Urbanism}

Segregation along the line of class, ethnicity, and race has characterized cities in the West, where these identity markers often cross-cut to produce discernable habitation boundaries (Cutler, Glaeser, and Vigdor 1999; Logan and Parman 2017). Ethnic "ghettos" or "enclaves," two sides of the same segregation coin, are sustained over time through perverse land use policy that results in high housing values, reproducing spatial inequality (Rothstein 2017). Local governments can "decide what gets built, what doesn't get built, and where the building happens," leading to "segregation by design" (Trounstine 2018). While economic disparity generates incentives for residents to move out of "low opportunity" to "high opportunity" neighborhoods, informational barriers, psychological and sociological constraints, search costs, and rent affordability inhibit mobility of marginalized groups (Bergman et al. 2019). When marginalized groups are geographically concentrated, segregation enables discrimination in public goods provision, further perpetuating spatial disparities (Trounstine 2016). Such processes that drive and maintain residential segregation are the "structural linchpin[s]" of racial stratification in the United States (Pettigrew 1979).

Two competing theories have dominated accounts of urban residential segregation - spatial assimilation and place-stratification. According to the "spatial assimilation" theory, socio-economic status, rather than identity-based preferences, determines the spatial distribution of residents economic prosperity allows poor and marginalized to move from lower-quality to better-quality neighborhoods (Alba and Logan 1993; Clark 1986; Massey and Denton 1985). This mechanism is often used to explain why relatively economically mobile individuals from ethnic minority groups have moved from "ethnic enclaves" to prosperous white-dominated neighborhoods. In contrast, the 
"place-stratification" theory posits that segregated neighborhoods result from a complex interplay between individuals and institutions (Charles 2003; Logan and Molotch 1987). It underscores how powerful groups seek physical and social separation from subordinate groups, creating barriers to residential mobility for the latter. For example, residential segregation patterns in American cities do not reflect individual choices but are a product of prejudice and discrimination against racial minorities (Trounstine 2018). Recent work has, however, challenged these classical segregation hypotheses by calling for a more nuanced understanding of persistent residential segregation as the sorting of "social structure" (Krysan and Crowder 2017).

\subsection{Inter-group Contact, and Multi-scale Segregation}

The fundamental psychological effects of segregation are mediated through perceptions shaped by the nature of inter-group contact, or lack thereof (Enos 2017), and are at the heart of influential inter-group contact hypotheses (Allport 1954; Pettigrew 1979). Spatial scales modulate both the probability and intensity of inter-group contact. What is the appropriate spatial unit of segregation analysis from the perspective of contact hypothesis that posits a positive relationship between inter-group contact and inter-group tolerance? The association between residential segregation and outcome variables of interest (for example, health, economic mobility, etc.) are scale-contingent when inter-group contact is the dominant channel (Humphreys and Scacco 2020). ${ }^{1}$

That the experience of segregation for an individual resident is multi-scalar is somewhat tautological. A necessary preliminary for any spatial segregation analysis is to define a theoretically relevant neighborhood unit that is necessarily contingent on the outcome variable of interest. The question of where to measure segregation cannot be divorced from the question of why segregation is being measured in the first place. Consider a resident walking across the city starting from her home. As she begins her walk, the most immediate neighbors first come into picture, next she encounters the larger neighborhood that progressively transitions into a distinct new neighborhood, only for this process to be repeated as she covers the entire city (Helmreich 2003). Any combination

\footnotetext{
${ }^{1}$ Cf. Kasara (2013) and Ejdemyr, Kramon, and Robinson (2018) for recent attempts at explicitly accounting for spatial scales in studying the impact of segregation.
} 
of the steps traced by our resident is a scalar sequence that can potentially define a neighborhood. However, every such sequence represents a different experience that any measure of residential segregation must take into account (Olteanu, Randon-Furling, and Clark 2019). The spatial unit of analysis problem is especially salient in large diverse cities that comprise of many smaller segregated co-ethnic neighborhoods --- both enclaves and ghettos represent such homogeneous neighborhoods.

A variegated neighborhood structure is at the heart of cities as complex self-organizing systems shaped by interdependent and spatially-contingent socio-economic, political, and infrastructural factors (Bettencourt 2013). An immediate corollary of this conception of the city for social-spatial processes such as residential segregation is the salience of linkages across spatial scales. While the built environment (including infrastructure) is adequately described by the size of the city, the social, economic, and demographic processes cannot be fully accounted for by city size. City space is organized around work, services, or other groups, with smaller sub-elements that are "replications of the same form at different scales" so that cities acquire a "fractal" spatial geometry (Batty and Longley 1994) [pp. 43]. If the socio-spatial geometry of a city is fractal, residential segregation must also be described across overlapping spatial scales. However, the appropriate unit of analysis for characterizing residential segregation has received scant attention, especially in understanding how (if) it varies by city size (Olteanu et al. 2019).

\subsection{Does segregation vary by city size?}

The relationship between city size and the intensity of residential segregation was a conundrum that animated the earliest sociologists studying urban segregation. In the industrial West, some of the largest and most diverse cities are also the most segregated (Cutler et al. 1999). Explaining urbanism as a way of life, Wirth (1938) argued that larger cities facilitate greater interaction among individuals from potentially different socio-cultural backgrounds. However, once these diverse communities come to inhabit a city, "[t]hey tend to segregate from one another in the degree in which their requirements and modes of life are incompatible with one another and in the measure in which they are antagonistic to one another." Park (1915) observed in an influential essay 
that, "[t]he processes of segregation establish moral distances which makes the city a mosaic of little worlds which touch but do not interpenetrate." While modern scholarship has transcended the racial animosity assumptions implicit in these early studies, the relationship between city size and segregation intensity remains an outstanding puzzle --- especially in the Global South. ${ }^{2}$

Aggregate measures of segregation, especially in large and diverse cities, do not always appropriately portray actual individual experiences of segregation (Lee et al 2008). Statistically, aggregation introduces ecological inference problems resulting in the well-known Modifiable Areal Unit Problem, or the MAUP (Openshaw 1984). For example, residential segregation studies in the United States have shown how whites and racial minorities occupy non-overlapping enclaves within a census tract (Logan and Parman 2017; Wong 2004). The strong correlation between city size and measured segregation has been shown to vanish when moving the analysis from larger spatial aggregates to more compact ones (Krupka 2007). Thus, central to any residential segregation analysis is a theoretically grounded choice for the most appropriate spatial unit of analysis, data limitations notwithstanding (Wong 2003). Statistical concerns aside, an aggregate measure of segregation does not shed light on the nature or the extent of inter-group social interactions. An underlying assumption (if only implicit) in any residential segregation study is that demographic distribution is dialectically linked to the intensity of intergroup contact (Charles 2003; Clark 1991; Clark and Fossett 2008; Laurie and Jaggi 2003; Schelling 2006).

\subsection{The challenge of studying urban residential segregation in India}

Urban scholars rely on unit boundaries defined by national census operations as a neighborhood proxy. For instance, in the United States, census tracts - comprising around 4000 residents - is the preferred spatial unit of analysis (Iceland and Weinberg 2002; Massey and Denton 1987). The census of India, on the other hand, has historically released data on group compositions only at the ward level. However, wards are large heterogeneous aggregations with diversity across

\footnotetext{
${ }^{2}$ Even when contemporary scholarship has discarded the normative underpinnings of the first generation of segregation research, the technical apparatus developed to measure segregation continues to be influential (Taeuber and Taeuber 2008).
} 
class as well as caste. The average population of wards vary from 1500 to 6000 in small towns and municipalities, and going up to over 100,000 in metropolitan cities (Prasad 2006). Thus, wards in large cities can be as large as entire towns in many parts of the world, and hardly qualify as "neighborhoods."

Given data limitations, extant urban residential segregation portraits in India have relied on the ward as the spatial unit of analysis (Sidhwani 2015; Singh et al. 2019; Vithayathil and Singh 2012). Dalit bastis, or the lower caste neighborhoods are locally concentrated and often exist alongside upper-caste and upper-class enclaves, within the same ward. Dupont (2004) illustrates this starkly with an example from New Delhi, India's capital - 39\% of residents in Rajiv Gandhi Camp (an officially recognized slum) are from marginalized caste groups as opposed to only $7 \%$ share of marginalized groups in the adjoining government housing complex. In a study of the five largest metropolitan cities in India, Bharathi et al. (2019) show that the segregation of neighborhoods within a ward is greater than segregation of wards in a city.

The first ever systematic large- $n$ portrait of high-resolution residential segregation in urban India that we present here, helps us generate conjectures and hypotheses about how segregation is determined by multiple factors including economic distance, discriminatory experience, psychological perceptions of the neighborhood, social networks, place of work, and institutions of urban governance and planning. Our residential segregation snapshot also sheds light on how these factors interact with social mobility of groups. Above all, the persistence of residential segregation along the axes of traditional ascriptive identities is a puzzle for broader theories of modernization.

\section{Caste and Segregation}

Spatial segregation as a constitutive feature of India's caste society is centered on the overlap between caste and hereditary occupations that are graded along a purity-impurity axis. Indian villages are characterized by nucleated homogeneous hamlet clusters that follow a spatial 
hierarchy (Singh and Khan 1999; Srinivas 1959). ${ }^{3}$ The most significant spatial boundary in a village is the one between the formerly "untouchable" caste groups (administratively classified as Scheduled Castes, and self-identified as "Dalits," or the oppressed) and others. The Dalits, considered as "impure or untouchable castes," are consigned to habitations on the outskirts of the village proper (Singh 2015). Such spatial arrangements facilitate discriminatory practices in placement of, and access to, essential public goods such as water, schools, and health centers (Munshi and Rosenzweig 2016). These discriminatory practices, often as a result of spatial distribution of castes, lead to alienation of lower caste groups contributing to the widening of intergroup distances (Mukherjee 1999). Spatial segregation is also central to segmentation of cultural institutions such as places of worship. The overlap of caste with hereditary occupations results in a persistent congruence between caste and class in India's agrarian society (Béteille 1965; Ghurye 1969), adding further ballast to spatial segregation.

\subsection{The normative promise of urbanization in India}

The gradual breaking down of traditional discriminatory caste practices, including residential segregation, has been a longstanding normative promise of India's urbanization (Ambedkar 1948; Teltumbde 2001, 2020). Since caste-based spatial segregation in villages is tied to hereditary occupational structures, it has been assumed that the city with its vastly expanded occupational choices and anonymity will foster dissolution of caste boundaries. The long-held assumption that modern occupations in an urban setting precipitate class, rather than caste-based stratification (Srinivas 2003) has however not been subject to systematic empirical scrutiny. ${ }^{4}$

Even when empirically untested, cities have been assumed to be sites of social transformation, as much as sites of economic opportunity and mobility. B.R. Ambedkar, the principal author of independent India's constitution had advocated rapid urbanization and rural to urban migration as a means of escaping the countryside that he famously described as "den[s] of

\footnotetext{
${ }^{3}$ The national census data (2011, the latest available census year) for rural India shows that the average village is split into 3.9 nucleated hamlets in states where habitation cluster data is collected as part of the census exercise.

${ }^{4}$ However, in the absence of large-scale evidence, ethnographic case studies have uncovered how cities can reproduce and even strengthen constitutive elements of caste such as residential segregation (Banerjee and Mehta 2017).
} 
localism" (Ambedkar 1948). Migration patterns in India continue to be peppered with stories of lower caste migration from villages into cities to escape the caste hegemony prevalent in the rural areas (Chandavarkar 2009; Teltumbde 2001, 2020; Tumbe 2018). ${ }^{5}$

While the emancipatory promise of India's urbanization has only been partially redeemed, cities in India have offered avenues for economic mobility not available in the country. This economic mobility has resulted in a distinctive urban Dalit identity and new forms of social assertions (Rao 2009; Teltumbde 2020). The limited anonymity of the city has at least partially "obliterated caste distinctions, because it [is] impossible to maintain caste taboos or regulate contact in public conveyances" (Rao, 2009). However ethnographic case studies have documented how the city as a "liberating space of anonymity" has left residential segregation largely untouched so that even upwardly mobile Dalit residents in a city continue to be spatially segregated (Banerjee and Mehta 2017). Despite the share of lower castes in urban India increasing (Teltumbde 2020), larger cities in India continue to be characterized by pockets with negligible share of marginal groups (Bharathi et al. 2019; Mitra and Nagar 2018; Singh et al. 2019).

The promise that social status in urban India is determined by class-markers such as wealth, income, or education (Beteille 1997), has prompted contemporary scholars to assert that "caste is losing, and will continue to lose, its strength" (Prasad 2010). However, available evidence suggests that caste continues to characterize economic relations and socio-economic outcomes and opportunities, like education, health, labor markets and electoral politics in contemporary urban India (Deshpande 2011; Kothari 1995; Thorat and Neuman 2012). Agglomeration driven urban growth has not been able to assimilate the precariat as promised. When the overwhelming majority of this precariat is drawn from historically marginalized caste groups, a segmented class-based spatial organization in urban India (Kundu 2011c) overlaps with a caste-based spatial structure (Motiram and Vakulabharanam 2020).

\footnotetext{
${ }^{5}$ Indeed, such migration dates back to colonial times. Between 1872 and 1881, large number of Mahars (a formerly "untouchable" group) moved from the hinterland to urban centers in Maharashtra (especially to Bombay and Nagpur) not only chasing new economic opportunities in textile mills or the rapidly expanding rail network, but also to escape subordination in the countryside (Rao 2009).
} 


\subsection{Existing accounts of caste-based urban residential segregation}

Extant accounts of urban segregation, even when not based on high-resolution and largescale data, point to why urban India is not a "melting pot" that facilitates social mobility. Instead, Indian cities stubbornly mirror and reproduce the rural socioeconomic realities in urban settings (Sahoo 2016). Using coarse ward-level data, Vithayathil and Singh (2012) have shown how castebased segregation is more pronounced than class-based segregation. ${ }^{6}$ While systematic quantitative characterization of neighborhood-scale segregation has not been possible in India owing to data limitations (Bharathi et al. 2019), ethnographic accounts have explored pathways that engender neighborhood segregation. Rental market discrimination is one of them which pushes the marginalized caste groups to the urban fringes, thus replicating the spatial hierarchy of the countryside. Studying inter-caste relations in Tiruppur (a textile center in southern India), Carswell, Neve, and Heyer (2018) argue, how Dalits are often forced to conceal their identities in order to access rental housing. Similarly, Roberts (2016) finds that Paraiyars (a marginalized caste group in South India) of Anbu Nagar slum of Chennai systematically misreport their caste status to enumerators conducting official surveys.

Narratives of caste-based discrimination in Indian cities can also be found in various subaltern autobiographies. Sharankumar Limbale, in Akkarmashi, describes the town of Latur (in Maharashtra) as one with caste herds, where the only space available for Dalits is in the ghettos (Limbale 2003). Tulasi Ram, in Manikarnika, describes how he lied about his caste-identity to secure livable accommodation, and how he was duly thrown out when the landlord discovered him to be a Dalit (Ram 2014). Ram's experience mirrors that of Ambedkar's many decades ago, who famously had to present himself as a Parsi gentleman to secure rental housing in Baroda, where he was employed as a high-ranking official following his doctoral studies (Ambedkar 2005).

Even the semantics of neighborhood names in urban India reflect underlying segregated spatial hierarchies. Neighborhoods (bastis) where lower castes are clustered in informal settlements

\footnotetext{
${ }^{6}$ The cross-cutting relationship between caste and class can be more pronounced at neighborhood scales (Motiram and Vakulabharanam 2020).
} 
are routinely labeled through lower caste markers - for example, "Balmiki Nagar," or "Kumhar village" (Balmiki and Kumhar, are both historically marginalized social groups). At the other end of the spectrum, enclaves dominated by upper echelons of the caste and class hierarchy are identified by names such as "Dollar Colony," or "Palm Meadows" that also embed them in global economic networks. Yet, detailed anthropological accounts of individual neighborhoods or towns notwithstanding (Gist 1957; Hazlehurst 1970; Lynch 1967), there are no systematic large- $n$ portraits of such neighborhood-scale segregation in urban India.

\section{A High-Resolution Multi-Scale Segregation Portrait of Urban India}

A necessary "preanalytic" preliminary (Schumpeter 1954) that must precede any analytic account of neighborhood-scale segregation is the development of an empirically tractable definition of what constitutes a "neighborhood." A neighborhood, as we have discussed above, is ultimately a phenomenological question centered on both in-group and out-group interactions. However, an adequate analytical definition of a neighborhood must also account for empirical tractability even while maintaining fidelity to lived experiences.

The decennial Indian national census collects caste information along three broad aggregate social categories - Scheduled Castes (SCs), Scheduled Tribes (STs), and a residual "Other" (OTH). ${ }^{7}$ Historically, the national census released group share data only at the aggregate urban ward scale. The latest available census data (2011), however, also provides group share information at the level of enumeration blocks (EBs). We use these census enumeration blocks as our analytical neighborhood unit of choice as it adequately approximates psychological perceptions of a neighborhood. EBs in urban India typically contain around 100-125 households with an average population of 650-700 individuals. As a point of reference, census tracts in the United States - the preferred spatial unit of analysis in large swathes of the segregation literature that continues to be focused on the US - contain around 4000 residents. Census blocks in urban India are spatially

\footnotetext{
${ }^{7}$ There is no data on religious shares below the level of a sub-district, which makes religion-based segregation studies a rarity. However, attempts have been made by Susewind (2017) using voter data, and by Adukia et al. (2019) using the socio-economic caste census of 2011 (SECC).
} 
coterminous with the built environment so that boundaries demarcating streets, major institutional buildings, etc., coincide with EB boundaries. This "spatial proximity and connectivity" (Roberto 2018) feature of census enumeration blocks make them particularly well-suited as analytic representations of a neighborhood. The built environment features such as a main thoroughfare, or a large gated enclave can disrupt local connectivity and define the phenomenology of a neighborhood (Roberto 2018; Roberto and Hwang 2015).

In Figure-1, we illustrate why a census block is a good choice as an analytic representation of a neighborhood, and also why the urban ward - the extant spatial unit of segregation analysis - is problematic. The top panel of the figure zooms in on a randomly selected portion of the census population distribution map for Bengaluru - India's third largest city that had a population of 8.5 million in 2011 distributed across 198 wards and over 16,000 census enumeration blocks. Of the 198 wards in Bengaluru, not a single ward had a population of less than 40,000 in 2011 (Mehta et al. 2013). The top panel shows how wards themselves are heterogeneous despite clear evidence for intra-ward segregation, thus suggesting why residential segregation must be studied at the neighborhood scale.

The large intra-ward variation in the population share of marginalized groups (SC/ST) shows why urban wards with 30,000 to 200,000 residents can hardly describe what is perceived as a neighborhood by residents. The bottom panel of Figure-1 provides direct visual evidence for why the enumeration block, as opposed to a ward, is a good analytical representation of what residents perceive as a neighborhood. The panel shows a photograph of two adjacent (and vastly heterogeneous) blocks drawn from a common ward. ${ }^{8}$ The settlement pattern as depicted in the bottom panel of Figure 1 is not an exotic exception but reflects the structure of urban economy in India where a large precariat, residing in informal housing tenements complements middle class participants in formal, and often global economic networks (Mitra 2010).

\footnotetext{
${ }^{8}$ This photograph comes from a large "rapid ethnography" project, Imagining Bengaluru Imagining Bangalore (IBIB), led by the first author of this paper. The project involved over 400 professional master's students from a leading public institution in Bengaluru, India spending three days in neighborhoods spread across 75 randomly selected wards across Bengaluru visually documenting residents as well as the built environment. All the material collected from the project is available in an open-source, non-copyrighted archive. The online archive with all material will debut in 2001-21.
} 


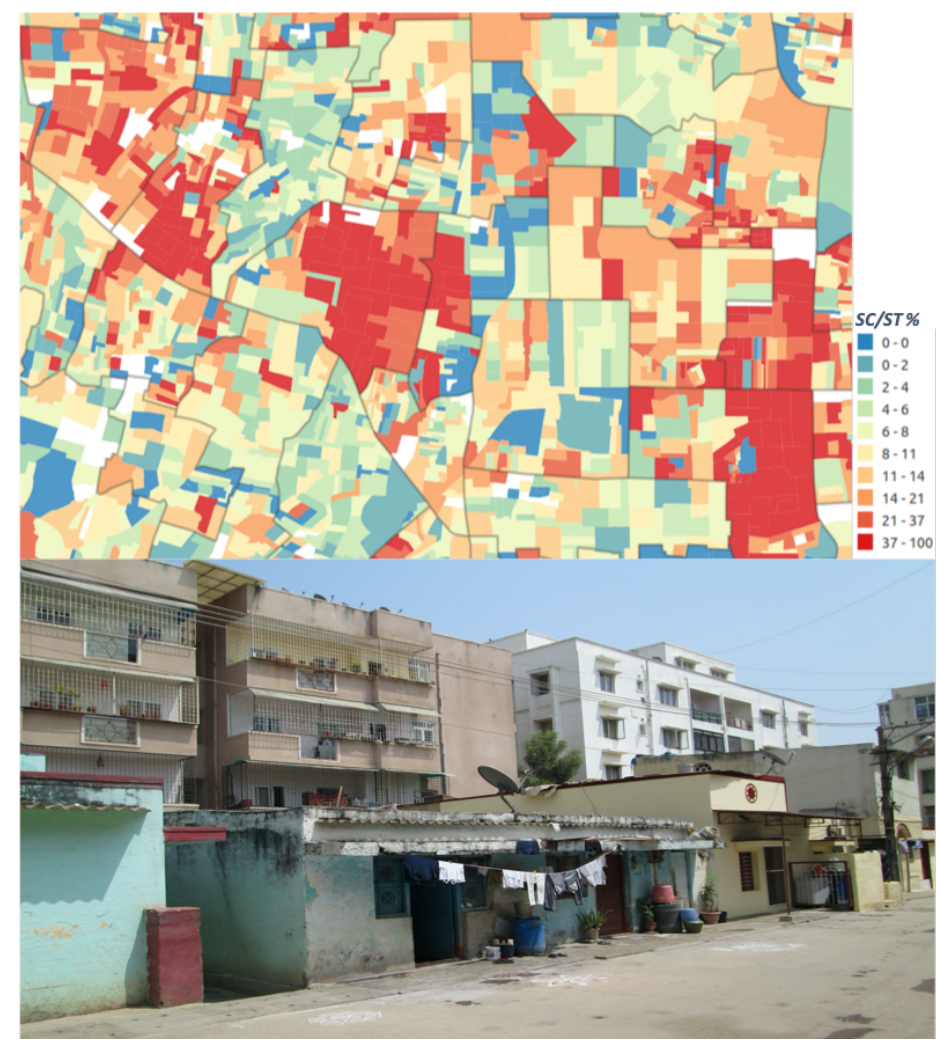

Figure 1: Wards and Census Blocks in Bengaluru. The upper panel shows the distribution of the SC/ST population in the city of Bengaluru at the block-level. The panel also shows ward boundaries (thicker lines) to illustrate how diverse wards can contain segregated neighborhoods (census enumeration blocks). The bottom panel shows two distinct census enumeration blocks abutting each other (in a common ward). Map in the top panel prepared by the authors using data from Census of India. The picture in the bottom panel is from the open-source IBIB Project (see main text for details).

The empirical case for the census enumeration block as the analytic neighborhood is further bolstered by the fact that the size of EBs are constant across urban India and do not vary with city size unlike wards ( $c f$. Figure-A1 in the appendix). One of our principal empirical goals is to characterize the relationship between residential segregation and city size, and this exercise requires that the size of the neighborhood spatial units is city-size invariant.

\subsection{Measuring Segregation}

We measure segregation using the workhorse dissimilarity index (Taeuber and Taeuber 1976). Dissimilarity Index $(D)$ is a measure of evenness that is usefully interpreted as the proportion of the minority group population that has to be "moved" to achieve perfect evenness (Massey and Denton 1989). We compute the index, both at the ward and enumeration block (EB) levels to capture the ward-city and neighborhood-ward dissimilarities in population shares. 


$$
D=0.5 \sum_{i=1}^{N}\left|\frac{S_{i}}{\mathrm{~S}}-\frac{r_{i}}{\mathrm{R}}\right|
$$

Here, $s_{i}$ is the group share of SCST population in $i^{\text {th }}$ block/ward, and $S$ is total SCST population in the higher aggregate (ward, or city). In the above equation, $r_{i}$ represents the rest of the population in respective block/ward, while $R$ represents the rest of the population in the aggregate spatial scale. The dissimilarity index, $D$, is bound in the interval $[0,1]$, with 0 representing perfectly even population distribution, and 1 , perfect segregation. We have chosen the Dissimilarity Index $(D)$, not only because it is easy to interpret, and is the most widely used metric, but also to ensure that our results are comparable to extant quantitative studies of spatial segregation in urban India that have all used the same index (Bharathi et al. 2019; Sidhwani 2015; Singh et al. 2019; Vithayathil and Singh 2012). To be consistent with existing empirical accounts, we compute the dissimilarity index by grouping the two marginalized groups into an aggregate SCST category, rather than use a generalized dissimilarity index for more than two subgroups (Morgan 1975; Sakoda 1981). The boundary between marginalized groups (SCs and STs) and the rest of the population also represents the boundary between "touchability" and "untouchability" which defines the social structure of group distance (Guru 2009). This group distance - a central constitutive feature of this boundary between "caste" and "outcaste" - is at the heart of residential segregation in rural India and our goal is to examine if such segregation is replicated in a rapidly urbanizing India. This strategy is also consistent with our primary interest - the relationship between urbanization and the salience of traditional ascriptive identities.

At both the ward and enumeration block levels, we also measure group diversity using the standard Herfindahl Hirschman fractionalization metric (Hirschman 1964). Measuring fractionalization in our spatial units allows us to study the relationship between spatial segregation and diversity. Diversity is of course a necessary precondition for any residential segregation - a perfectly homogenous city cannot be segregated any further. ${ }^{9}$

\footnotetext{
${ }^{9}$ Like the dissimilarity index, fractionalization metric is easy to interpret - it represents the probability that two randomly chosen individuals from a spatial unit belong to two different social groups.
} 


\subsection{Fractal Segregation: Evidence from the 2011 National Census Data}

To present a snapshot of the extent of neighborhood-scale residential segregation, we use the latest national census data (2011) at the EB level for the 147 of the largest cities in India (all cities with at least 0.3 million residents). Together, these cities contain 333,046 EBs nested within 10,048 wards. In Figure-2 we demonstrate why residential segregation must be characterized across spatial scales, and even more crucially why the neighborhood-scale should not be neglected as has been the practice in extant quantitative studies. Panel-A of Figure-2 shows kernel density plots for distribution of diversity in wards and blocks across all cities. As seen from the panel, wards are diverse while the enumeration blocks are not. Homogeneous neighborhoods (EBs) within diverse wards provide preliminary evidence for why the hitherto neglected intra-ward segregation might account for most of the segregation in urban India. The nature of the markedly bi-modal distribution characterizing neighborhood-scale diversity also shows why homogeneous neighborhoods appear to be exceptions rather than the rule.

Panel-B of Figure-2 provides a more direct preliminary evidence for "fractal segregation" across spatial scales. The panel shows standard Lorenz curves for SCST population at both block and ward levels across all the 147 cities - EBs are far more unequal than the wards in terms of the population shares of the SCST group. Gini coefficients reported in the panel, however, must be read with caution as stylized facts about intra-ward segregation from an abstract aggregate city. Even with this caveat, a greater than $10 \%$ difference in the Gini index between neighborhood $(0.71)$ and wards (0.6) suggests that marginalized groups in urban India are highly segregated into co-ethnic enclaves with a fractal "geometry" (Simmel 2009). While the concentration of marginalized groups in select wards has been shown in previous studies, our preliminary description of the data in PanelB of Figure-2 shows how city-ward segregation is reproduced within the ward giving it a fractal character. 

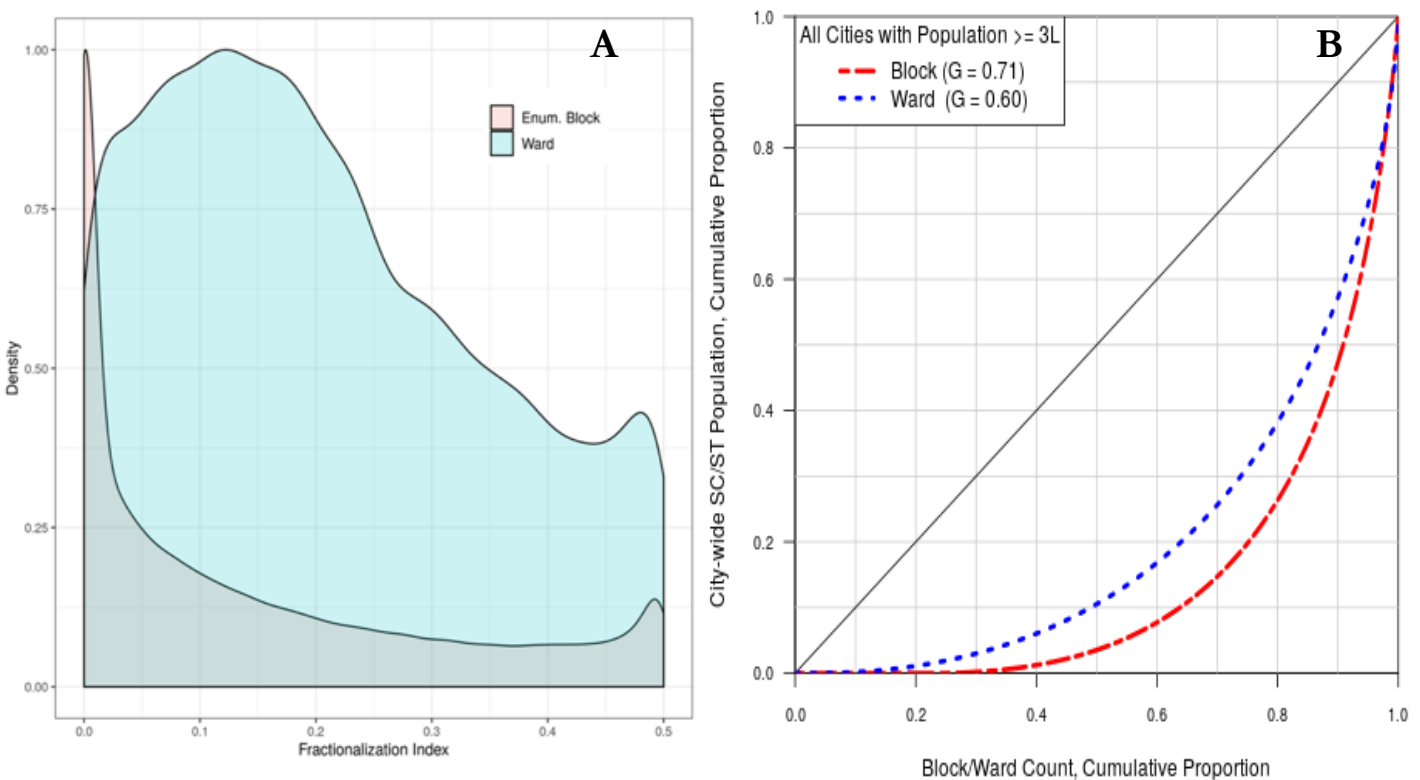

Figure 2: Wards versus Neighborhoods. Panel-A shows kernel densities of distribution of diversity (fractionalization index) measured at block $(\mathrm{n}=333,046)$ and ward $(\mathrm{n}=10,048)$ across 147 largest cities in India. Panel-B computes segregation (measured as Gini Index) for a hypothetical aggregate city containing 10.048 wards and 333,046 neighborhoods (enumeration blocks). Data from Census of India (2011). See main text for details.

Further evidence for the fractal geometry of segregation in urban India is provided in Figure-3. We computed dissimilarity index at two levels - city-ward, and ward-EB to measure how ward population distribution is different from the city-wide distribution, and also characterize how individual neighborhoods (EBs) are different from the wards that contain them. Panel-A of Figure-3 shows city-ward dissimilarity as a function of ward diversity (fractionalization). The panel shows how ward-level segregation is largely independent of the overall city-level diversity. This panel is also consistent with previous findings that have shown how lack of substantial variation in wardlevel segregation across a disparate range of cities. In Panel-B of the same figure, we have plotted ward-EB dissimilarity index as a function of ward diversity, for all 10,048 wards in our sample. We find that, even at the neighborhood-scale, segregation is independent of the ward diversity. The inset in Panel-B of Figure-3 shows the cumulative density function for ward-block dissimilarity index - once again showing wide variability across the range of theoretical values that the index can 
assume. The appendix table enumerates city-ward dissimilarity index as well as the ward-EB dissimilarity index for each one of the 147 cities in our sample.
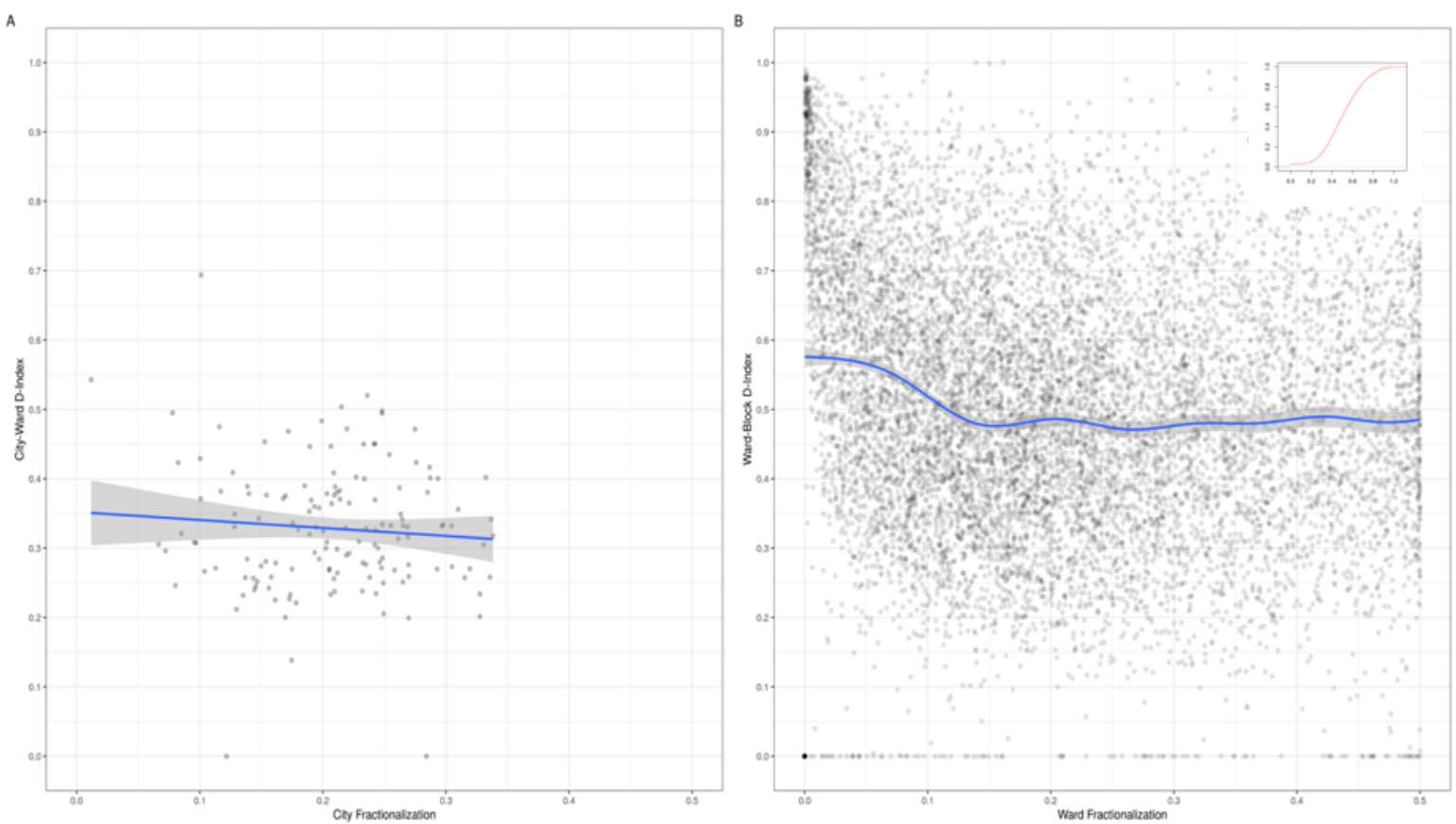

Figure 3: Diversity and Segregation. Panel-A shows the relationship between city-wide diversity and ward-level segregation $(n=147)$. Panel- $B$ depicts the relationship between ward diversity and intra-ward segregation (measured as ward-block dissimilarity index; $n=10,048)$. The inset in Panel-B shows the cumulative density function (ECDF) of ward-block dissimilarity index. LOESS fit with 95\% confidence bands are shown in both panels. Authors' computations; data from Census of India (2011). See main text for further details.

\subsection{City Size and Residential Segregation}

Caste's association with occupation is an important channel (second only to endogamy) that enables its intergenerational transmission (Jodhka 2016, 2017). Larger cities offer diverse economic opportunities representing a more varied occupational choice set, potentially opening up newer avenues for socio-economic mobility. Thus, the nature of the relationship between city size and residential segregation is not only important in characterizing patterns of urbanization, but also offers a window into whether urbanization dilutes caste identities rooted in an agrarian regime. In Figure-4, we present the relationship between city size and residential segregation for all the 147 cities in our sample which provides clear evidence for size-invariant fractal segregation. The largest metropolitan centers in our sample are over forty times bigger than the smallest towns, yet the 
segregation indices (measured at both the ward level as well as neighborhood scale) are independent of city size.

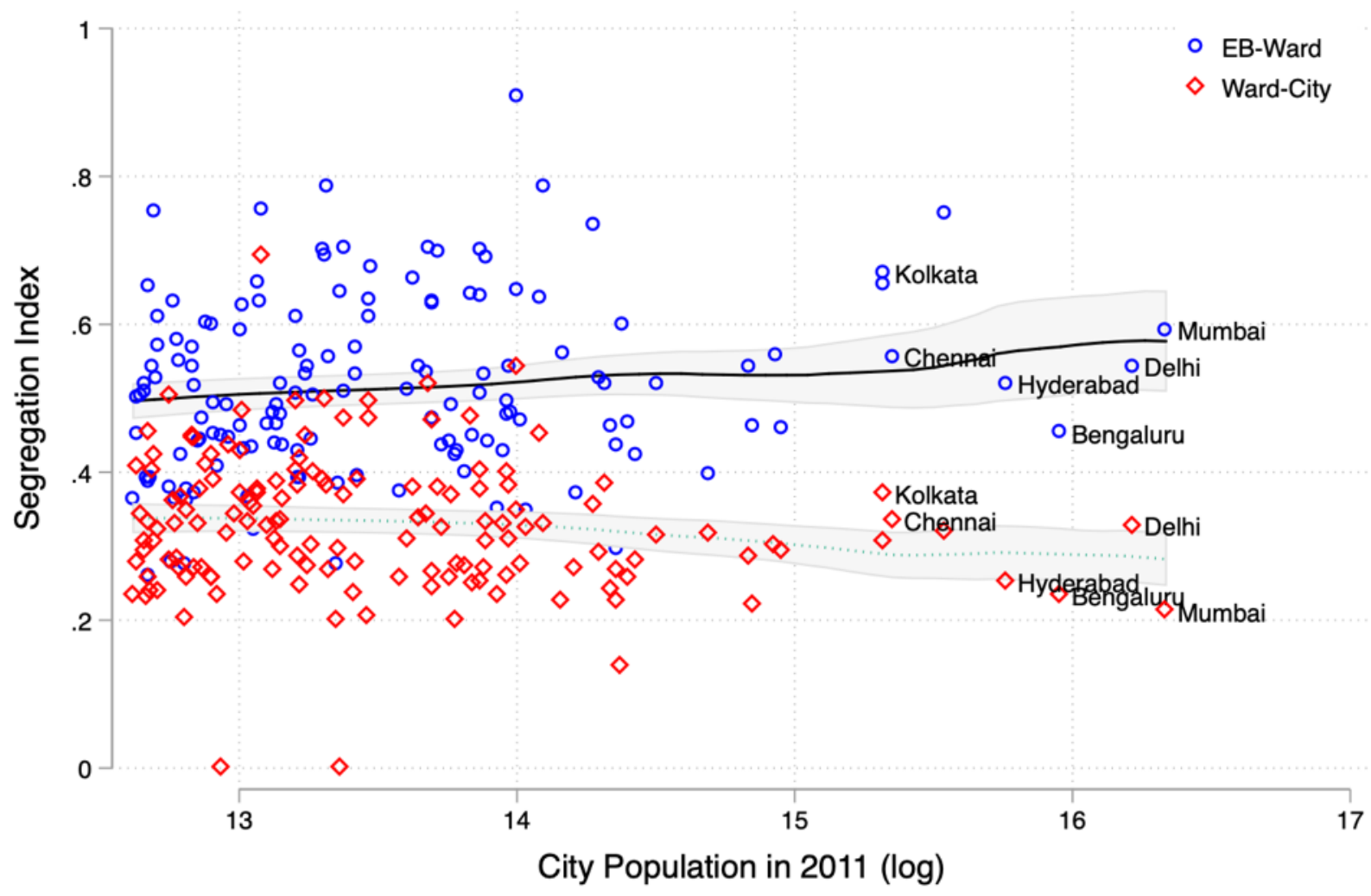

Figure 4: City size and Segregation. The figure depicts segregation at ward and neighborhood levels. The blue-colored points show city-ward dissimilarity across all 147 cities (these points are identical to ones in Panel-A of Figure-3). The red-colored points on the graph represent median ward-block dissimilarity index for each city. These medians are computed from ward-block dissimilarity computed over 10,048 wards and 333,046 blocks in these wards. For both the ward-level and neighborhood-scale segregation, we have identified the six largest cities in India. LOESS fits with 95\% confidence bands are shown. Data from Census of India (2011). See main text for further computation details.

While we have depicted median ward-EB dissimilarity for each city as the representative level of intra-ward neighborhood-scale segregation, the core arguments around the relationship (or more accurately, lack of relationship) between segregation and city size remains unaltered when other summary statistics are used. Neighborhood-scale segregation is independent of city size when (population weighted) mean ward-EB dissimilarity, or some other quantile instead of the median is used. However, what is not immediately obvious from Figure-4 is the relationship between fractal segregation (across two spatial scales represented in the figure) and city size. The figure shows that for nearly all cities in our sample, intra-ward segregation is greater than segregation at the ward- 
level. In other words, neighborhoods within a ward are more "dissimilar" from the respective wards containing them, than wards are dissimilar from the city as a whole.

A

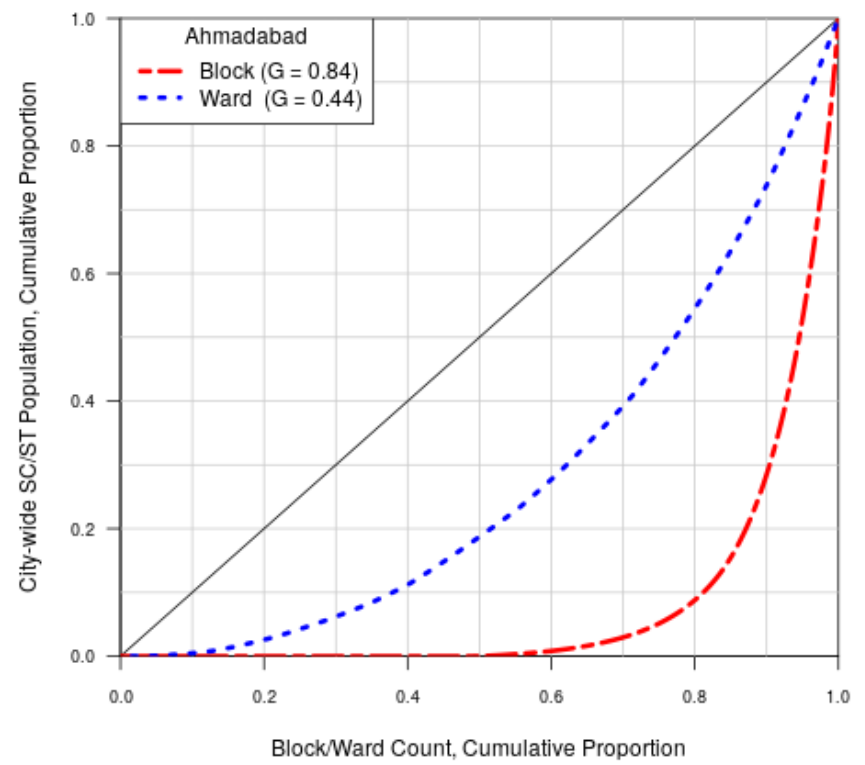

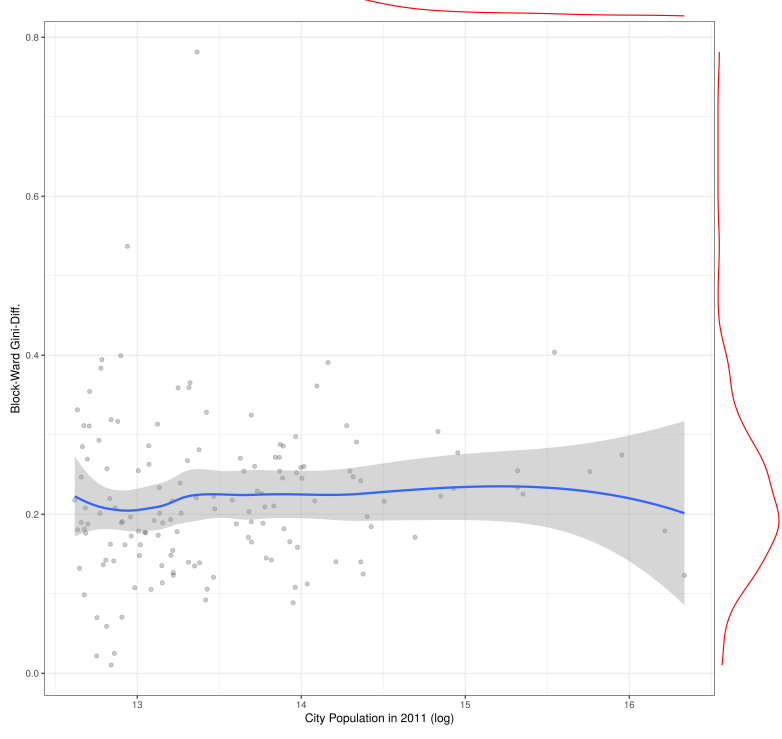

Figure 5: Fractal Segregation. Panel-A depicts ward-level and block-level segregation for the western Indian city of Ahmedabad. The Gini coefficients reported in Panel-A measure how the distribution of marginalized groups (SCST) in wards and neighborhoods (enumeration blocks) of Ahmedabad are different from the distribution in the city as a whole. The difference in Gini coefficients computed at block and ward levels (the area between the two Lorenz curves is proportional to this difference) is an indicator of intra-ward segregation. Panel-B plots this Gini-difference for all 147 cities in our sample as a function of city size. LOESS fit with 95\% confidence band is shown. The panel also shows distribution of this difference as well as city size (log) as marginal distribution plots. Authors' computations from Census of India (2011) data. See main text for further details.

In Figure-5, we present the relationship between fractal segregation and city size more directly. As an illustrative example, we have chosen the western Indian city of Ahmedabad, which has been the subject of residential segregation by religion (Susewind 2017) as well as caste (Banerjee and Mehta 2017). In Panel-A of the figure, the EB level Lorenz curve for Ahmedabad shows that approximately $60 \%$ of the neighborhoods in the city do not contain any residents from marginalized groups (SCST). Taken together, the two Lorenz curves (at the ward and EB levels) also illustrate the fractal nature of segregation. Wards in Ahmedabad are segregated by caste (the blue-colored Lorenz curve with Gini of 0.44 ), and there is further segregation within a ward so that the Lorenz curve at the block level has a Gini of 0.84 . The area between the two Lorenz curves is proportional to the difference between Gini coefficients computed at block and ward levels. In 
Panel-B of Figure-5, we investigate the relationship between this Gini difference and city size for all 147 cities in our sample. The scale-independence of neighborhood level segregation is clearly seen here - neighborhoods in larger metropolitan centers with over ten million residents are as segregated as towns, which are over forty times smaller.

\subsubsection{Fractal segregation is persistent across India}

The fractal segregation pattern described in Figure-4 and Figure-5 is not a geographic artifact but is an all-India phenomenon as illustrated in Figure-6 that maps onto each one of the 147 cities in our sample. The map represents both neighborhood-scale segregation as well as city size. As seen from the map, the highly segregated cities are geographically spread across the country.

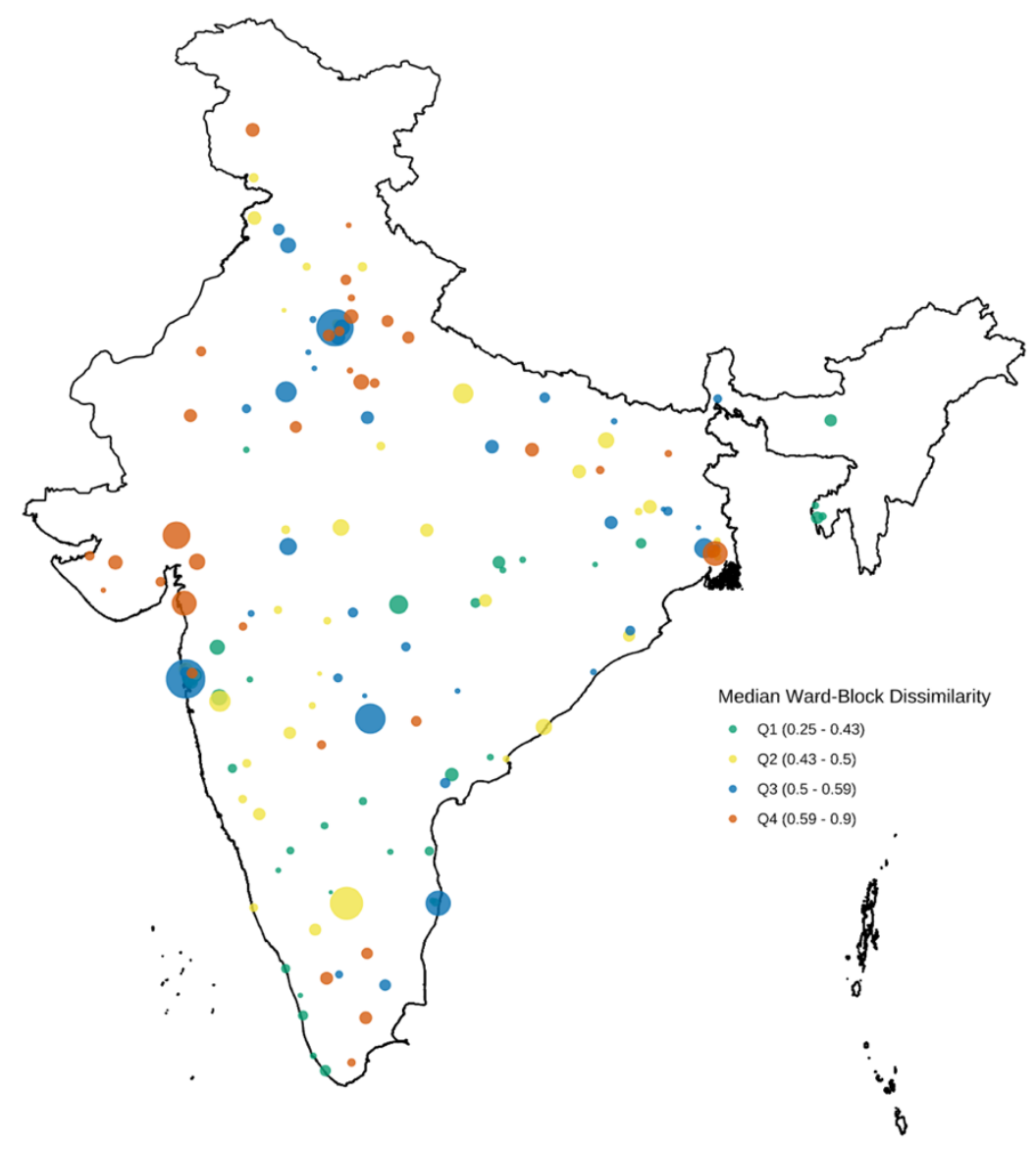

Figure 6: The Geography of Residential Segregation. The figure maps each of the 147 cities in our sample and depicts both city size and median ward-block dissimilarity index as a measure of neighborhood-scale intra-ward residential segregation. Cities are represented by bubble points whose size is proportional to population and color-coded to represent four quartiles of neighborhood-scale segregation (measured as median ward-block dissimilarity in a city). Authors' computation from Census of India data (2011). Also cf. Appendix-table for details about data used in this map. 


\subsubsection{Segregation does not vary by city growth driven by agglomeration effects}

If greater opportunities for occupational mobility in a large city are expected to weaken caste rigidities, it is also fair to assume that faster growing urban centers will likely accord more such opportunities. Several Indian cities are now among the fastest growing in the world. ${ }^{10}$ Between 2001 and 2011 urban India grew faster than rural India in absolute terms despite officially accounting for less than a third of India (Kundu 2011b, 2011a). Any impact of growth on residential segregation is likely to be on temporal scales of generations, rather than a decade. We, therefore, examine the relationship between growth of cities between 1961 and 2011, and residential segregation in Figure-7. In Panel-A, median neighborhood-scale residential segregation is represented as a function of population growth between 1961 and 2011. The faster growing cities do indeed display residential segregation levels that are marginally lower than cities that have not grown as fast. Two large metropolitan centers, Mumbai and Kolkata have recorded the lowest growth rates in our sample of 147 cities. This apparent anomaly is accounted for by the growth of satellite towns in the larger metropolitan region. In Panel-B of Figure-7 we identify these satellite towns in a plot describing the relationship between population growth (1960-2011) and population in 2011. ${ }^{11}$ Taken together, the two panels in Figure-7 add further ballast to our finding that rapid urbanization has not resulted in the dismantling of traditional ascriptive identities - at least as seen through the lens of residential segregation, a constitutive feature of India's agrarian caste order.

\footnotetext{
${ }^{10}$ For a list, see https://www.iied.org/worlds-fastest-growing-cities

${ }^{11}$ We represent satellite towns around Delhi, Mumbai, and Kolkata.
} 

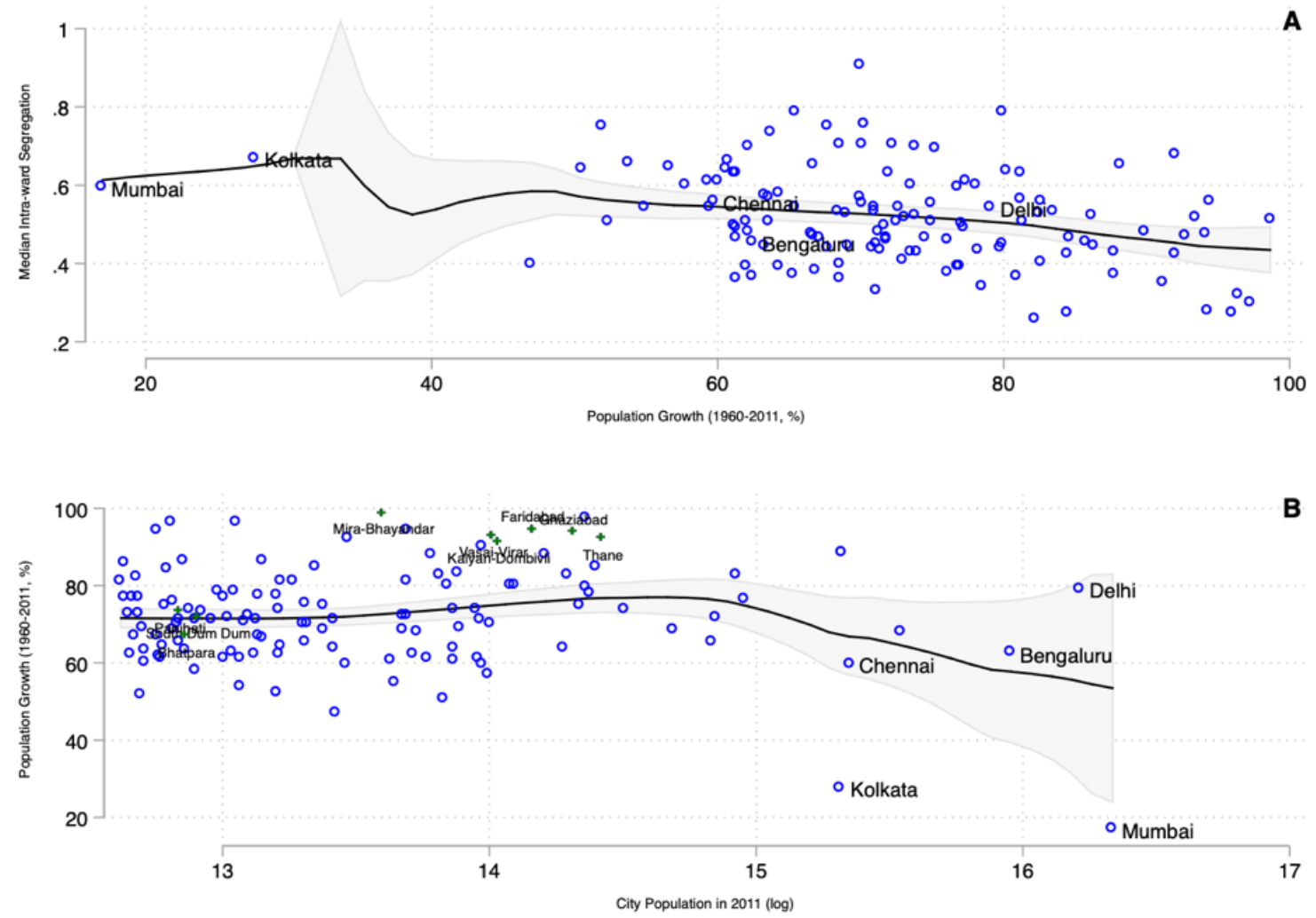

Figure 7: Growth and Residential Segregation Geography of Residential Segregation. Panel-A maps each of the 147 cities in our sample. The top panel shows neighborhood-scale segregation (median ward-block dissimilarity index) as a function of percentage population growth between 1961 and 2011. The bottom panel shows population growth between 1961 and 2011 as a function of 2011 population (log). Besides the five large metropolitan centers from Panel-A this panel also identifies satellite towns around Mumbai, Delhi, and Kolkata. LOESS fits with 95\% confidence bands are shown in both panels. Authors' computations from Census of India data $(1961,2011)$. Refer to the main text for further details.

\subsubsection{Power-law Distribution of City Size}

The relationship between residential segregation and city size is trivially contingent on the population distribution across cities in our sample. We have thus far not shown that the actual city size distribution in India is consistent with implicit theoretical assumptions underlying the relationship between city size and urban forms including residential segregation. In Figure- 8 we present the size distribution of India's urban administrative units at all three spatial scales that we have used in this paper - city, ward, and EB. As seen from the figure, the spatial units are power law distributed at all three spatial scales. The power law distribution of the spatial units at all three scales helps cement our primary result that residential segregation is independent of city size (Basu and Bandyapadhyay 2009; Devadoss et al. 2016). 

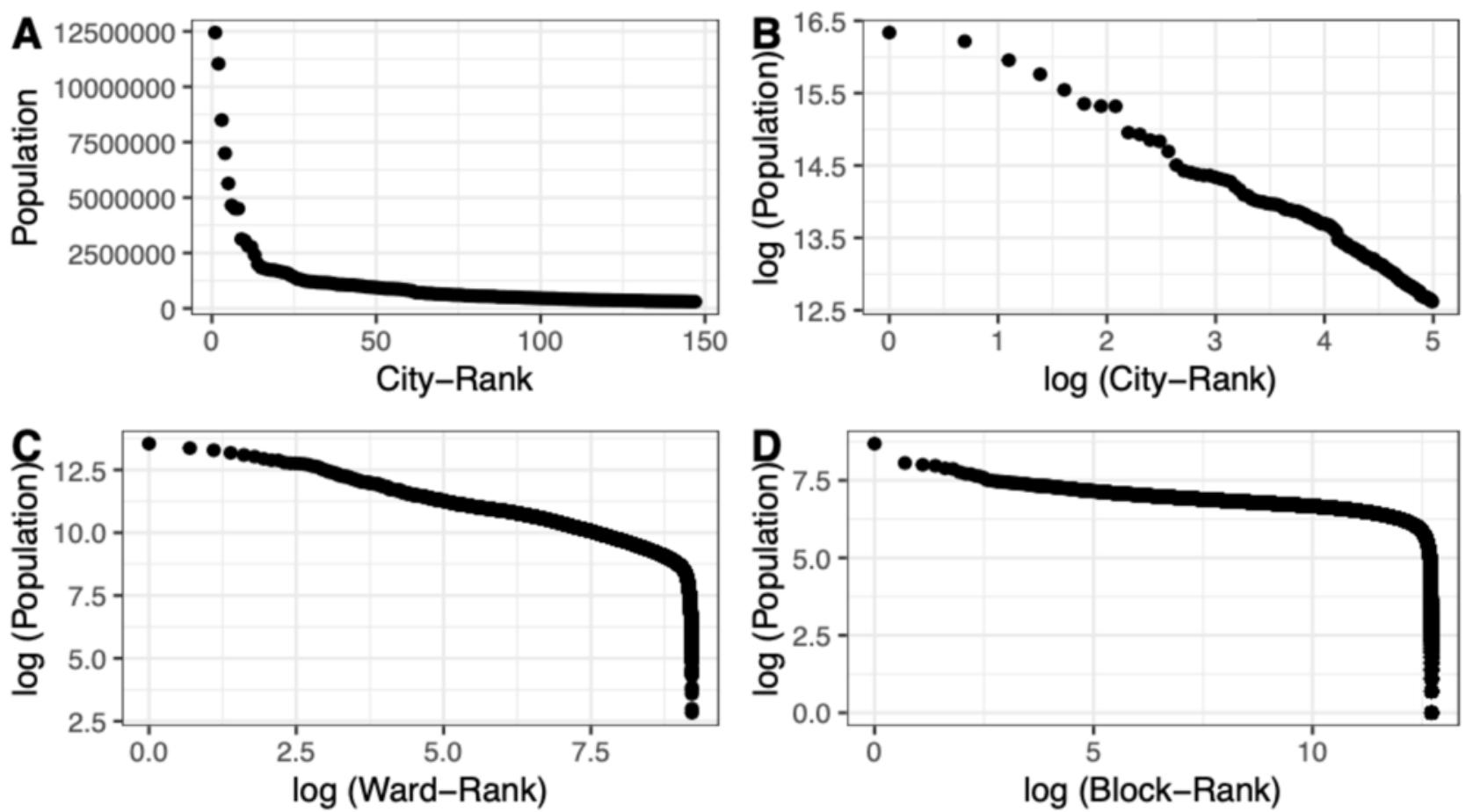

Figure 8: The "Zipf Law" and Urban Jurisdictions in India. Authors' computation from Census of India data (1961, 2011). Refer to the main text for further details. The figure shows the power-law distribution of urban units in India at three different spatial scales --- city (Panel A, Panel B), ward (Panel C), and neighborhood (enumeration block, Panel D). Authors' computation from Census of India data (2011). Refer to the main text for further details.

\subsubsection{Intra-ward segregation is independent of ward size}

In Figure-9, we present the relationship between ward-size and intra-ward neighborhoodscale residential segregation across 10.048 wards from the 147 cities in our sample. The figure shows that the extent of intra-ward segregation is independent of ward size. The maximum size of the density bins in the plot is under $1.3 \%$. The (non) effect of ward size on neighborhood segregation in Figure-9 when juxtaposed against Panel-B of Figure-3 incontrovertibly show that caste-based segregation of neighborhood in Indian cities is all pervasive with no discernable modulation in larger and more diverse wards. Combined with our results showing a lack of correlation between city size and caste-based segregation, we find strong support for residential segregation that not only possesses a fractal geometry cutting across scales but is also sizeindependent at any given scale. Our city and ward results are not driven by variations in SCST proportions as a function of city or ward size ( $c f$. Figure-A2 in the appendix). 


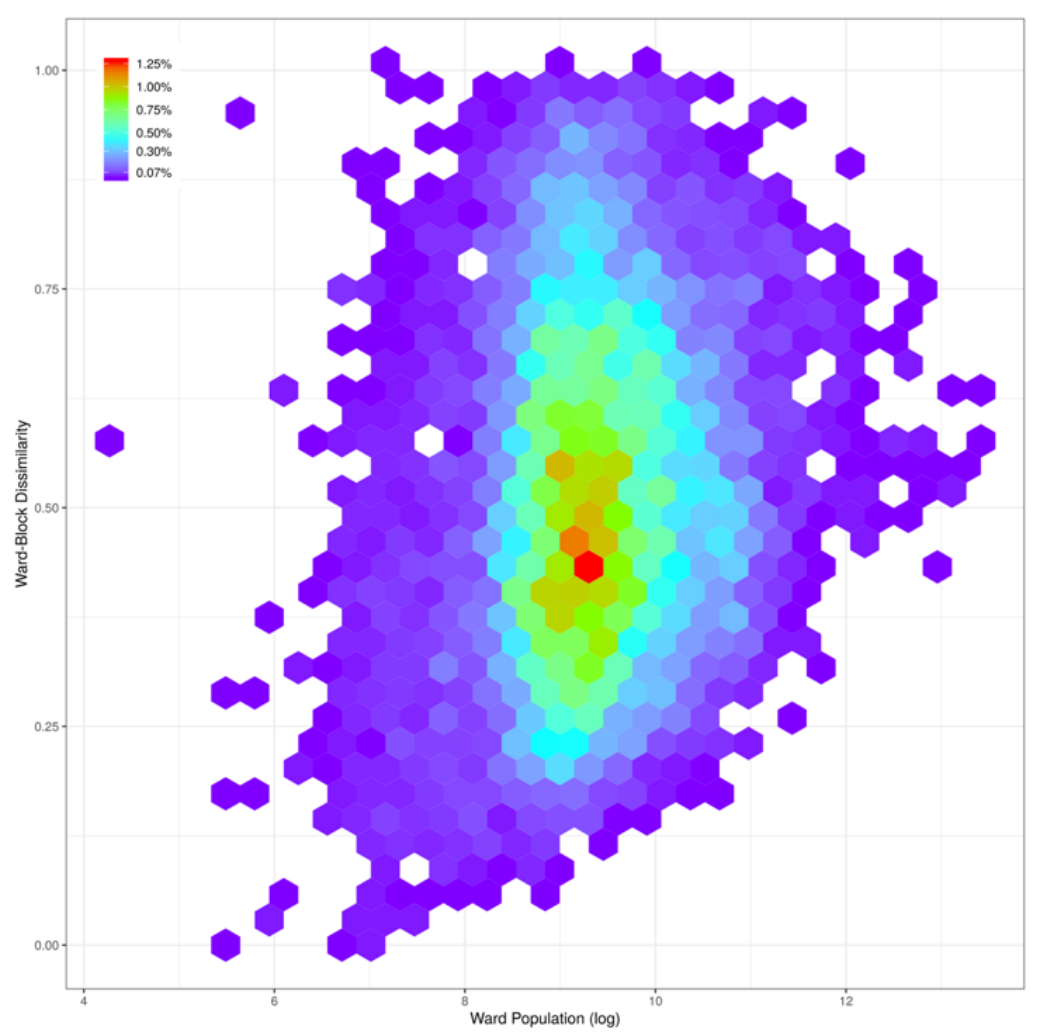

Figure 9: Ward Size and Intra-ward Segregation ("binned" plot). Authors' computation from Census of India data (2011). Refer to the main text for further details

\section{Discussion}

The evidence for size-invariant residential segregation across multiple scales (wards, and neighborhood) clearly suggests that one of the central constitutive features of the hierarchical caste order - spatial segregation - has largely remained untouched during India's urbanization process. To underscore our findings, in Figure-10, we show how the urban segregation geometry that we have described here is structurally similar to that of rural India. Indian villages are segregated at two different levels. First, not all villages are equally diverse, or not even as diverse as regional districts and sub-districts in which they are located. Panel-A of Figure-10 shows the uneven distribution of marginalized social groups (SC/ST) in rural India across 595,983 villages (represented as quartiles). 

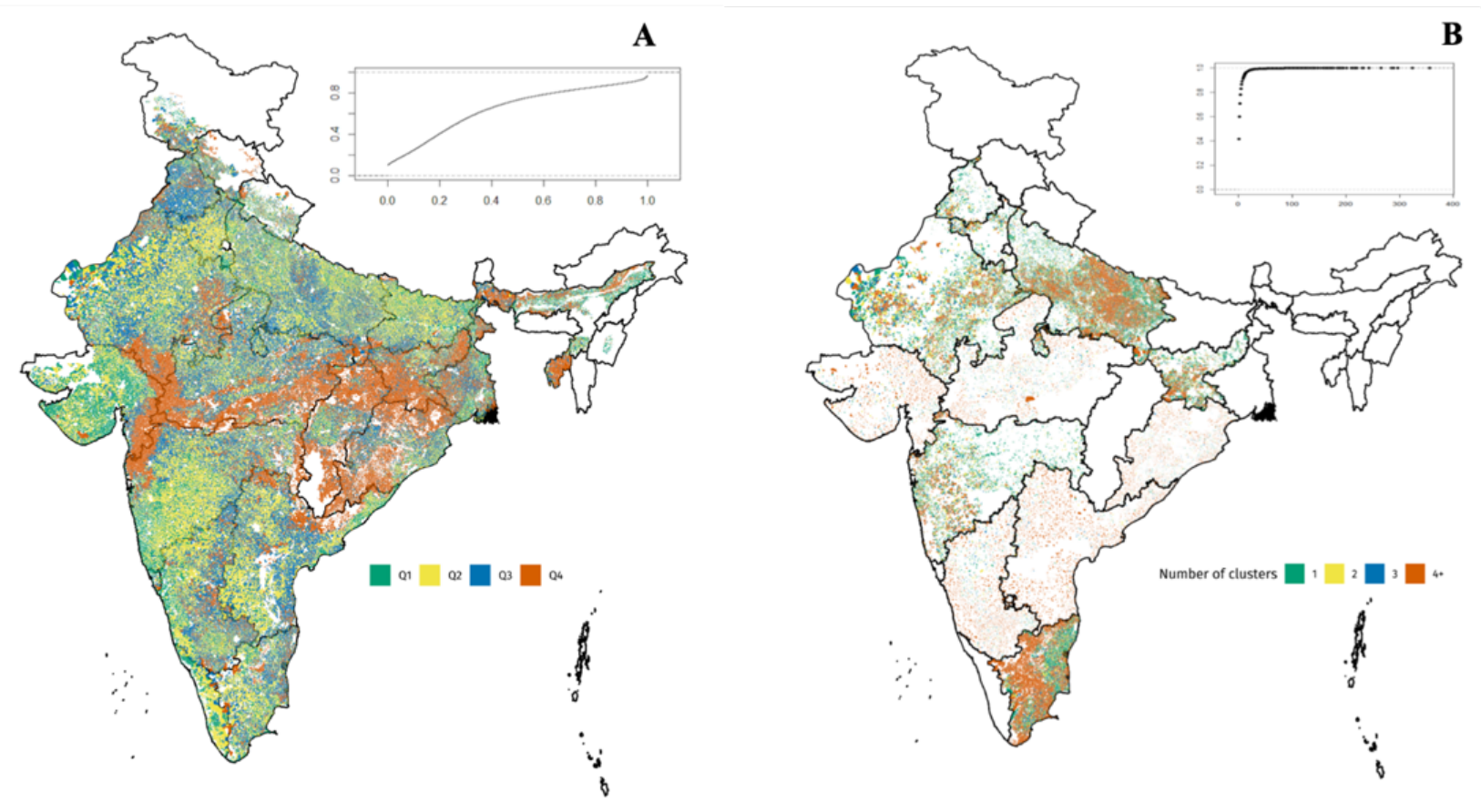

Figure 10: Fractal Geometry of Spatial Segregation in Rural India. Panel-A shows proportion of SC/ST in villages across India $(\mathrm{n} \sim 600,000)$ by quartiles. Urban areas and missing data are shown as white space. Q1 =0-10.6\% SCST; Q2 = 10.6-27.5\% SCST; Q3 = 27.5-58.1\% SCST; $Q 4=58.1-100 \%$ SCST. For both panels insets show cumulative density (ECDF) distribution. While Panel-A shows how villages as a whole are segregated, Panel-B describes intravillage segregation by presenting number of segregated nucleated hamlets within a village. This intra-village hamlet information is available for approximately 20\% of villages in India (missing data and urban areas shows as white space). Authors' computation from Census of India data (2011). Village polygons from Survey of India. Refer to main text for further details.

Villages in India are almost perfectly segregated almost by caste so that each village with multiple caste groups is spatially organized into nucleated homogeneous hamlets. Panel-B of Figure-10 depicts this intra-village segregation by showing the number of hamlets in villages where this information was collected as part of the national census exercise. The cumulative distribution function in the inset of this panel shows how intra-village segregation is pervasive. For our purposes, the fractal geometry of segregation in rural India represented by the two panels of Figure10 is structurally similar to spatial segregation in India's largest metropolitan centers.

Our finding that the intensity of residential segregation is not significantly impacted by the extent of urbanization, calls into question a central normative assumption of India's modernization. Further, we have also shown that residential segregation patterns are largely independent of rates of urbanization. Our results amplify existing findings showing how rapid urbanization during years of high economic growth (Kohli 2006) have created highly stratified urban spaces (Vakulabharanam 
and Motiram 2012). "Recombinant urbanization" (Balakrishnan 2019) has allowed elites within the agrarian regime to seamlessly transfer their dominance into the urban space.

A crucial factor determining the relationship between urbanization and ascriptive institutions is the nature of middle class and its (in)ability to build cosmopolitan structures that transcend traditional identities. That the Indian middle class has failed to forge a cross-ethnic "class" identity even as urbanization has opened up opportunities is related to how the middle class in India is united by patterns of consumption rather than as "driver[s] of modernity" (Kapur 2017). Spatially, this consumptive class has retreated into enclaves of privilege (Bhattacharya and Sanyal 2001) leaving the vast precariat to seek marginal spaces including informal settlements and slums which become their 'first home' in a new city (Banerjee, Pande, and Walton 2012). Given the continued congruence between caste and class (Deshpande and Ramachandran 2019), any apparent classbased spatial segregation overlaps with caste-based segregation. Even as urbanization has reduced absolute poverty during the high-growth years, the marginalized groups have benefitted least (Datt, Ravallion, and Murgai 2020). Economic mobility, in terms of a rise in consumption, improved educational outcomes, and better employment opportunities, have been largely restricted to the upper castes (Asher, Novosad, and Rafkin 2018; Krishna 2017). For the miniscule few from marginalized social groups, who aided by affirmative action, have made the transition to middle class, spatial barriers continue to persistent (Banerjee and Mehta 2017). Urban spatial segregation continues to thrive in an urbanization regime that suffers from the "territorial impossibility of governance, justice, and development" (Roy 2009). Our central finding - the persistence of residential segregation - is also consistent with studies that have found similar persistence of other constitutive features of caste such as the practice of untouchability (Thorat and Joshi 2020). ${ }^{12}$

The growth of market institutions in urban India continue to rely on caste networks which have been crucial for the celebrated entrepreneurial dynamism that has powered economic growth starting in the 1990s (Damodaran 2009; Iyer, Khanna, and Varshney 2013). However, such

\footnotetext{
${ }^{12}$ More than 20 percent of urban households practice untouchability in some form or the other even as the eradication of untouchability was one of the founding tenets of modern India.
} 
resource-rich caste networks are also exclusionary in nature, especially for the most marginalized social groups (Munshi 2014, 2019). When caste networks play a domineering role, it also impacts where migrants locate when they migrate from villages to cities, especially historically marginalized groups who are forced to move to "ghettos" or "slums." Wacquant (2015) makes the case that urban marginality follows multi-layered and multi-structural process that is contingent on the "institutional mechanisms that produce, reproduce and transform the network of positions to which its supposed members are dispatched and attached."

Urban scholars have also emphasized the role that politics plays in the construction of space (Orum and Gottdiener 2019; Roy 2009; Wacquant 2008). While both economic as well as political elites respond to rent-seeking opportunities in the political economy of urban land, informal politics that caters to marginalized caste and class groups is paternalistic in character, prioritizing parochial neighborhood-level issues over the demand for equitable access to housing or amenities (Heller, Mukhopadhyay, and Walton 2016). Electoral politics and Dalits' participation in the political process has however failed to translate into full citizenship right including spatial equality in access to public services (Bertorelli et al. 2017).

Our findings, therefore, force a rethink of how (if) urbanization can lead to the erosion of caste in India. Caste is clearly not (yet) a "relic of the past" (Ambedkar 2004). Newer modes of politics in urban India (Auerbach 2016; Thachil 2017) are markedly distinct from traditional "identity politics" of the hinterland (Beteille 2012; Srinivas 2003). Yet, such political processes have not rendered ascriptive institutions archaic and obsolete. The large-scale evidence for "fractal urbanism" that we have presented here call for the rethinking of a central normative promise of urbanization - cities as sites of economic, political, and social transformation. 


\section{REFERENCES}

Adukia, A., S. Asher, P. Novosad, and B. Tan. 2019. Residential Segregation in Urban India.

Alba, Richard D. and John R. Logan. 1993. "Minority Proximity to Whites in Suburbs: An Individual-Level Analysis of Segregation.”American Journal of Sociology 98(6):1388-1427.

Allport, G. W. 1954. The Nature of Prejudice. Addison-Wesley.

Ambedkar, B. R. 1948. "Draft Constitution - Discussion.” in Dr. Babasaheb Ambedkar's Writings and Speeches (Vol. 13), edited by V. Moon. Government of Maharashtra Education Department.

Ambedkar, B. R. 2004. “Castes in India: Their Mechanism, Genesis and Development.” Pp. 131-53 in Readings in Indian Government And Politics Class, Caste, Gender.

Ambedkar, B. R. 2005. "Waiting for a Visa.” Retrieved

(http://www.columbia.edu/itc/mealac/pritchett/00ambedkar/txt_ambedkar_waiting.html).

Asher, Sam, Paul Novosad, and Charlie Rafkin. 2018. Intergenerational Mobility in India: Estimates from New Methods and Administrative Data.

Auerbach, Adam Michael. 2016. "Clients and Communities.” World Politics 68(1):111-48.

Balakrishnan, Sai. 2019. "Recombinant Urbanization: Agrarian-Urban Landed Property and Uneven Development in India.” International Journal of Urban and Regional Research 43(4):617-32.

Banerjee, Abhijit, Rohini Pande, and Michael Walton. 2012. Delhi's Slum-Dwellers: Deprivation, Preferences and Political Engagement among the Urban Poor.

Banerjee, Biswajit and J. B. Knight. 1985. "Caste Discrimination in the Indian Urban Labour Market.” Journal of Development Economics 17(3):277-307.

Banerjee, Dyotana and Mona G. Mehta. 2017. "Caste and Capital in the Remaking of Ahmedabad." 
Contemporary South Asia 25(2):182-95.

Basu, B. and S. Bandyapadhyay. 2009. "Zipf's Law and Distribution of Population in Indian Cities." Indian Journal of Physics 83(11):1575-82.

Batty, M. and P. A. Longley. 1994. Fractal Cities: A Geometry of Form and Function. Academic Press.

Bergman, Peter, Raj Chetty, Stefanie DeLuca, Nathaniel Hendren, Lawrence F. Katz, and Christopher Palmer. 2019. Creating Moves to Opportunity: Experimental Evidence on Barriers to Neighborhood Choice. w26164.

Bertorelli, Ebony, Patrick Heller, Siddharth Swaminathan, and Ashutosh Varshney. 2017. "Does Citizenship Abate Class?” Economic \& Political Weekly LII(32):47-57.

Beteille, Andre. 1997. “India’s Middle-Class.” Internationale Politik 52(3):17-20.

Beteille, Andre. 2012. Caste, Class and Power: Changing Patterns of Stratification in a Tanjore Village. Oxford University Press.

Béteille, André. 1965. Caste, Class, and Power: Changing Patterns of Stratification in a Tanjore Village. Berkeley: University of California Press.

Bettencourt, L. M. A. 2013. "The Origins of Scaling in Cities.” Science 340(6139):1438-41.

Bhan, Gautam. 2019. “Notes on a Southern Urban Practice.” Environment and Urbanization 31(2):639-54.

Bharathi, Naveen, Deepak Malghan, and Andaleeb Rahman. 2019. "Neighbourhood-Scale Residential Segregation in Indian Metros.” Economic \& Politcal Weekly 54(30):64-70.

Bhattacharya, R. and K. Sanyal. 2001. "Bypassing the Squalor: New Towns, Immaterial Labour and Exclusion in Post-Colonial Urbanisation.” Economic \& Political Weekly 46(31):41-48.

Carswell, Grace, Geert De Neve, and Judith Heyer. 2018. "Caste Discrimination in Contemporary 
Tamil Nadu: Evidence from the Tiruppur Textile Region.” Pp. 172-206 in Contested Hierarchies, Persisting Influence: Caste and Power in Twenty-first Century India, edited by S. Jodhka and J. Manor. Orient Blackswan.

Chandavarkar, Rajnayaran. 2009. History, Culture and the Indian City. Cambridge: Cambridge University Press.

Charles, Camille Zubrinsky. 2003. "The Dynamics of Racial Residential Segregation.” Annual Review of Sociology 29(1):167-207.

Chetty, Raj, Nathaniel Hendren, and Lawrence F. Katz. 2016. “The Effects of Exposure to Better Neighborhoods on Children: New Evidence from the Moving to Opportunity Experiment.” American Economic Review 106(4):855-902.

Clark, W. A. V. 1986. "Residential Segregation in American Cities: A Review and Interpretation." Population Research and Policy Review 5(2):95-127.

Clark, W. A. V. 1991. "Residential Preferences and Neighborhood Racial Segregation: A Test of the Schelling Segregation Model.” Demography 28(1):1.

Clark, W. A. V. and M. Fossett. 2008. "Understanding the Social Context of the Schelling Segregation Model.” Proceedings of the National Academy of Sciences 105(11):4109-14.

Cutler, David M., Edward L. Glaeser, and Jacob L. Vigdor. 1999. "The Rise and Decline of the American Ghetto.” Journal of Political Economy 107(3):455-506.

Damodaran, Harish. 2009. India's New Capitalists: Caste, Business, and Industry in a Modern Nation. Permanent Black.

Datt, Gaurav, Martin Ravallion, and Rinku Murgai. 2020. "Poverty and Growth in India over Six Decades.” American Journal of Agricultural Economics 102(1):4-27.

Desai, Sonalde and Amaresh Dubey. 2011. "Caste in the 21st Century India." Competing Narratives, EPW 46(11). 
Deshpande, Ashwini. 2011. The Grammar of Caste: Economic Discrimination in Contemporary India. Oxford University Press.

Deshpande, Ashwini and Rajesh Ramachandran. 2019. "Traditional Hierarchies and Affirmative Action in a Globalizing Economy: Evidence from India.” World Development 118:63-78.

Devadoss, Stephen, Jeff Luckstead, Diana Danforth, and Sherzod Akhundjanov. 2016. "The Power Law Distribution for Lower Tail Cities in India." Physica A: Statistical Mechanics and Its Applications 442:193-96.

Dupont, Véronique. 2004. "Socio-Spatial Differentiation and Residential Segregation in Delhi: A Question of Scale?" Geoforum 35(2):157-75.

Ejdemyr, Simon, Eric Kramon, and Amanda Lea Robinson. 2018. "Segregation, Ethnic Favoritism, and the Strategic Targeting of Local Public Goods.” Comparative Political Studies 51(9):1111-43.

Enos, Ryan. 2017. The Space Between Us. Cambridge: Cambridge University Press.

Ghurye, G. S. 1969. Caste and Race in India. Bombay: Popular Prakashan.

Gist, Noel P. 1957. “The Ecology of Bangalore, India: An East-West Comparison.” Social Forces $356-65$.

Glaeser, Edward L. 2011. Triumph of the City: How Our Greatest Invention Makes Us Richer, Smarter, Greener, Healthier, and Happier. Penguin Random House.

Guru, Gopal. 2009. “Archaeology of Untouchability.” Economic \& Political Weekly 44(37):39-56.

Hazlehurst, Leighton W. 1970. "Urban Space and Activities.” Urban India: Society, Space and Image. Richard G. Fox Ed 186-95.

Heller, Patrick, Partha Mukhopadhyay, and Michael Walton. 2016. "Cabal City : Regime Theory and Indian Urbanization." 
Helmreich, William B. 2003. The New York Nobody Knows: Walking 6,000 Miles in the City. Princeton University Press.

Hirschman, Albert O. 1964. "The Paternity of an Index." American Economic Review 54(5):76162.

Humphreys, Macartan and Alexandra Scacco. 2020. “The Aggregation Challenge.” World Development 127:104806.

Iceland, John and Daniel H. Weinberg. 2002. Racial and Ethnic Residential Segregation in the United States 1980-2000. Bureau of Census.

Iyer, Lakshmi, Tarun Khanna, and Ashutosh Varshney. 2013. "Caste and Entrepreneurship in India." Economic \& Political Weekly 48(6):52-60.

Jodhka, Surinder. 2017. Caste in Contemporary India. Routledge.

Jodhka, Surinder S. 2016. “Ascriptive Hierarchies: Caste and Its Reproduction in Contemporary India." Current Sociology 64(2):228-43.

Kapur, Devesh. 2017. “How Will India’s Urban Future Affect Social Identities?” Urbanisation 2(1):1-8.

Kasara, Kimuli. 2013. "Separate and Suspicious: Local Social and Political Context and Ethnic Tolerance in Kenya." The Journal of Politics 75(4):921-36.

Kohli, Atul. 2006. "Politics of Economic Growth in India, 1980-2005." Economic \& Political Weekly 41(13):1251-59.

Kothari, Rajni. 1995. Caste in Indian Politics. Orient Blackswan.

Krishna, Anirudh. 2017. The Broken Ladder. Cambridge: Cambridge University Press.

Krupka, Douglas. 2007. “Are Big Cities More Segregated? Neighbourhood Scale and the Measurement of Segregation." Urban Studies 44(1):187-97. 
Krysan, Maria and Kyle Crowder. 2017. Cycle of Segregation. Russell Sage Foundation.

Kundu, Amitabh. 2011a. "Method in Madness: Urban Data from 2011 Census.” Economic \& Political Weekly 40(46):13-16.

Kundu, Amitabh. 2011b. "Politics and Economics of Urban Growth." Economic \& Political Weekly 46(20):10-12.

Kundu, Amitabh. 2011c. Trends and Processes of Urbanisation in India Human Settlements Group, IIED Population and Development Branch, UNFPA Urbanization and Emerging Population Issues 6.

Laurie, Alexander J. and Narendra K. Jaggi. 2003. "Role of 'Vision' in Neighbourhood Racial Segregation: A Variant of the Schelling Segregation Model." Urban Studies 40(13):26872704.

Limbale, Sharankumar. 2003. Akkarmashi [The Outcaste]. Oxford University Press.

Logan, John R. and Harvey Molotch. 1987. Urban Fortunes: The Political Economy of Place. University of California Press.

Logan, Trevon D. and John M. Parman. 2017. "The National Rise in Residential Segregation.” The Journal of Economic History 77(1):127-70.

Lynch, Owen M. 1967. "Rural Cities in India: Continuities and Discontinuities.” India and Ceylon: Unity and Diversity 142-58.

Massey, Douglas S. and Nancy A. Denton. 1985. "Spatial Assimilation as a Socioeconomic Outcome." American Sociological Review 50(1):94.

Massey, Douglas S. and Nancy A. Denton. 1987. "Trends in the Residential Segregation of Blacks, Hispanics, and Asians: 1970-1980.” American Sociological Review 802-25.

Massey, Douglas S. and Nancy A. Denton. 1989. "Hypersegregation in U.S. Metropolitan Areas: Black and Hispanic Segregation along Five Dimensions.” Demography 26(3):373. 
Mehta, Vishal K., Rimi Goswami, Eric Kemp-Benedict, Sekhar Muddu, and Deepak Malghan. 2013. "Social Ecology of Domestic Water Use in Bangalore." Economic \& Political Weekly $48(15): 40-50$.

Mitra, Arup. 2010. "Migration, Livelihood and Well-Being: Evidence from Indian City Slums." Urban Studies 47(7):1371-90.

Mitra, Arup and Jay Prakash Nagar. 2018. "City Size, Deprivation and Other Indicators of Development: Evidence from India." World Development 106:273-83.

Morgan, Barrie S. 1975. “The Segregation of Socio-Economic Groups in Urban Areas: A Comparative Analysis." Urban Studies 12(1):47-60.

Mosse, David. 2018. "Caste and Development: Contemporary Perspectives on a Structure of Discrimination and Advantage." World Development 110:422-36.

Mosse, David. 2019. "The Modernity of Caste and the Market Economy." Modern Asian Studies 147.

Motiram, Sripad and Vamsi Vakulabharanam. 2020. Intra-City Inequalities, Neighborhoods and Economic Development. 502.

Mukherjee, Ramakrishna. 1999. "Caste in Itself, Caste and Class, or Caste in Class.” Economic \& Political Weekly 34(27):1759-61.

Mumford, Lewis. 1961. The City in History: Its Origins, Its Transformations, and Its Prospects. Houghton Mifflin Harcourt.

Munshi, Kaivan. 2014. "Community Networks and the Process of Development." Journal of Economic Perspectives 28(4):49-76.

Munshi, Kaivan. 2019. “Caste and the Indian Economy.” Journal of Economic Literature 57(4):781-834.

Munshi, Kaivan and Mark Rosenzweig. 2016. Insiders and Outsiders: Local Ethnic Politics and 


\section{Public Goods Provision.}

Olteanu, Madalina, Julien Randon-Furling, and William A. V. Clark. 2019. "Segregation through the Multiscalar Lens." Proceedings of the National Academy of Sciences 116(25):12250-54.

Openshaw, S. 1984. "Ecological Fallacies and the Analysis of Areal Census Data." Environment and Planning $A$ 16(1):17-31.

Orum, Anthony M. and Mark Gottdiener. 2019. "New Urban Sociology.” The Wiley Blackwell Encyclopedia of Urban and Regional Studies (Pickvance 1977):1-5.

Park, Robert E. 1915. "The City: Suggestions for the Investigation of Human Behavior in the City Environment." American Journal of Sociology 20(5):577-612.

Pettigrew, Thomas F. 1979. "Racial Change and Social Policy." The ANNALS of the American Academy of Political and Social Science 441(1):114-31.

Prasad, Chandra Bhan. 2010. "New Order." Himal South Asian.

Prasad, Ram Narayan. 2006. Urban Local Self-Government in India. Mittal Publications.

Qadeer, M. A. 1974. 'Do Cities 'Modernize' the Developing Countries? An Examination of the South Asian Experience." Comparative Studies in Society and History 16(3):266-83.

Ram, Tulasi. 2014. Manikarnika (Hindi). Rajkamal Prakashan.

Rao, Anupama. 2009. The Caste Question: Dalits and the Politics of Modern India. University of California Press.

Ren, Xuefei. 2018. "From Chicago to China and India: Studying the City in the Twenty-First Century." Annual Review of Sociology 44(1):497-513.

Roberto, Elizabeth. 2018. "The Spatial Proximity and Connectivity Method for Measuring and Analyzing Residential Segregation.” Sociological Methodology 48(1):182-224.

Roberto, Elizabeth and Jackelyn Hwang. 2015. "Barriers to Integration: Physical Boundaries and 
the Spatial Structure of Residential Segregation."

Roberts, Nathaniel. 2016. To Be Cared For: The Power of Conversion and Foreignness of Belonging in an Indian Slum. University of California Press.

Rothstein, R. 2017. The Color of Law: A Forgotten History of How Our Government Segregated America. Liveright Publishing.

Roy, Ananya. 2009. "Why India Cannot Plan Its Cities: Informality, Insurgence and the Idiom of Urbanization." Planning Theory 8(1):76-87.

Sahoo, Niranjan. 2016. “A Tale of Three Cities: India’s Exclusionary Urbanisation.” ORF Issue Brief (156):1-8.

Sakoda, James M. 1981. “A Generalized Index of Dissimilarity.” Demography 18(2):245.

Schelling, T. C. 2006. Micromotives and Macrobehavior. WW Norton \& Company.

Schumpeter, Joseph. 1954. History of Economic Analysis. Oxford University Press Oxford, UK.

Sidhwani, Pranav. 2015. "Spatial Inequalities in Big Indian Cities.” Economic \& Political Weekly 50(22):55.

Simmel, G. 2009. Sociology: Inquiries into the Construction of Social Forms (2 Vols.). Brill.

Singh, Gayatri, Trina Vithayathil, and Kanhu Charan Pradhan. 2019. "Recasting Inequality: Residential Segregation by Caste over Time in Urban India." Environment and Urbanization $31(2): 615-34$.

Singh, Jai Pal and Mumtaz Khan. 1999. "Hindu Cosmology and the Orinetation and Segregation of Social Groups in Villages in Northwestern India." Geografiska Annaler: Series B, Human Geography 81(1):19-39.

Singh, Shamsher. 2015. "Residential Segregation and Access to Basic Amenities: A Village-Level Case Study." Journal, Review of Agrarian Studies 5(2):126-46. 
Soja, Edward D. 1980. "The Socio-Spatial Dialetic.” Annals of the Association of American Geographers 70(2):207-25.

Srinivas, M. N. 2003. "Obituary on Caste as a System.” Economic and Political Weekly 38(5):45559.

Srinivas, M. N. 1959. “The Dominant Caste in Rampura.” American Anthropologist 61(1):1-16.

Susewind, Raphael. 2017. "Muslims in Indian Cities: Degrees of Segregation and the Elusive Ghetto." Environment and Planning A 49(6):1286-1307.

Taeuber, Karl E. and Alma F. Taeuber. 1976. “A Practitioner's Perspective on the Index of Dissimilarity." American Sociological Review 41(5):884.

Teltumbde, Anand. 2001. Globalisation and the Dalits. Sanket Prakashan.

Teltumbde, Anand. 2020. Dalits: Past, Present and Future. Taylor \& Francis.

Thachil, Tariq. 2017. "Do Rural Migrants Divide Ethnically in the City? Evidence from an Ethnographic Experiment in India.” American Journal of Political Science 61(4):908-26.

Thorat, Amit and Omkar Joshi. 2020. “The Continuing Practice of Untouchability in India: Patterns and Mitigating Influences." Economic \& Political Weekly 55(2):36-45.

Thorat, Sukhadeo, Anuradha Banerjee, Vinod K. Mishra, and Firdaus Rizvi. 2015. "Urban Rental Housing Market.” Economic \& Political Weekly 27:47-53.

Thorat, Sukhadeo and Katherine S. Neuman. 2012. Blocked by Caste: Economic Discrimination in Modern India. Oxford University Press.

Trounstine, Jessica. 2016. "Segregation and Inequality in Public Goods." American Journal of Political Science 60(3):709-25.

Trounstine, Jessica. 2018. Segregation by Design. Cambridge University Press.

Tumbe, Chinmay. 2018. India Moving: A History of Migration by, New Delhi. Penguin India. 
Vakulabharanam, Vamsi and Sripad Motiram. 2012. "Understanding Poverty and Inequality in Urban India since Reforms: Bringing Quantitative and Qualitative Approaches Together.” Economic and Political Weekly 47(47-48):44-52.

Vithayathil, Trina and Gayatri Singh. 2012. "Spaces of Discrimination.” Economic \& Political Weekly 47(37):60-66.

Wacquant, L. 2008. Urban Outcasts: A Comparative Sociology of Advanced Marginality. Polity. Polity Press.

Wacquant, Loïc. 2015. "Revisiting Territories of Relegation: Class, Ethnicity and State in the Making of Advanced Marginality." Urban Studies 53(6):1077-88.

Wirth, Louis. 1938. “Urbanism as a Way of Life.” American Journal of Sociology 44(1):1-24.

Wong, David W. S. 2003. “A Framework Toward Measuring Segregation.” Geographical Analysis 35(3):179-94.

Wong, David W. S. 2004. “Comparing Traditional and Spatial Segregation Measures: A Spatial Scale Perspective." Urban Geography 25(1):66-82. 
APPENDIX: Segregation index for Indian cities with a 2011 population greater than three million

\begin{tabular}{|c|c|c|c|c|c|c|c|c|}
\hline CITY & $\begin{array}{l}\text { D } \\
\text { (Ward- } \\
\text { City) }\end{array}$ & $\begin{array}{l}\text { Median } \\
\text { D } \\
\text { (Block- } \\
\text { Ward) } \\
\end{array}$ & CITY & $\begin{array}{l}\text { D } \\
\text { (Ward- } \\
\text { City) }\end{array}$ & $\begin{array}{l}\text { Median } \\
\text { D } \\
\text { (Block- } \\
\text { Ward) } \\
\end{array}$ & CITY & $\begin{array}{l}\text { D } \\
\text { (Ward- } \\
\text { City) }\end{array}$ & $\begin{array}{l}\text { Median } \\
\text { D } \\
\text { (Block- } \\
\text { Ward) }\end{array}$ \\
\hline Agartala & 0.26 & 0.33 & Gorakhpur & 0.28 & 0.53 & Muzaffarpur & 0.28 & 0.58 \\
\hline Agra & 0.36 & 0.73 & $\begin{array}{l}\text { Greater } \\
\text { Mumbai }\end{array}$ & 0.21 & 0.59 & Mysore & 0.33 & 0.44 \\
\hline Ahmadabad & 0.32 & 0.75 & Gulbarga & 0.49 & 0.61 & Nagpur & 0.32 & 0.40 \\
\hline Ahmadnagar & 0.33 & 0.36 & Guntur & 0.24 & 0.57 & Nanded Waghala & 0.42 & 0.56 \\
\hline Ajmer & 0.40 & 0.51 & Gurgaon & 0.25 & 0.63 & Nashik & 0.27 & 0.37 \\
\hline Akola & 0.43 & 0.45 & Guwahati & 0.20 & 0.42 & Navi Mumbai & 0.23 & 0.35 \\
\hline Aligarh & 0.52 & 0.70 & GVMC & 0.23 & 0.44 & Nellore & 0.29 & 0.43 \\
\hline Allahabad & 0.31 & 0.54 & Gwalior & 0.25 & 0.51 & Nizamabad & 0.34 & 0.50 \\
\hline Alwar & 0.40 & 0.54 & Haora & 0.31 & 0.69 & Noida & 0.00 & 0.64 \\
\hline Ambattur & 0.35 & 0.32 & Hisar & 0.28 & 0.50 & Panihati & 0.27 & 0.52 \\
\hline Amravati & 0.47 & 0.51 & Hubli-Dharwad & 0.26 & 0.44 & Parbhani & 0.41 & 0.45 \\
\hline Amritsar & 0.40 & 0.50 & Indore & 0.31 & 0.52 & Patiala & 0.37 & 0.46 \\
\hline Asansol & 0.45 & 0.53 & Jabalpur & 0.33 & 0.44 & Patna & 0.24 & 0.46 \\
\hline Aurangabad & 0.38 & 0.48 & Jaipur & 0.30 & 0.56 & Pimpri Chinchwad & 0.27 & 0.30 \\
\hline Avadi & 0.28 & 0.28 & Jalandhar & 0.34 & 0.53 & Pune & 0.29 & 0.46 \\
\hline Barddhaman & 0.29 & 0.51 & Jalgaon & 0.36 & 0.43 & Raipur & 0.25 & 0.45 \\
\hline Bareilly & 0.38 & 0.70 & Jammu & 0.40 & 0.50 & Rajahmundry & 0.45 & 0.37 \\
\hline Belgaum & 0.33 & 0.47 & Jamnagar & 0.39 & 0.70 & Rajarhat Gopalpur & 0.42 & 0.45 \\
\hline Bellary & 0.23 & 0.41 & Jamshedpur & 0.39 & 0.40 & Rajkot & 0.33 & 0.79 \\
\hline Bengaluru & 0.23 & 0.45 & Jhansi & 0.33 & 0.46 & Rajpur Sonarpur & 0.32 & 0.49 \\
\hline Bhagalpur & 0.26 & 0.60 & Jodhpur & 0.40 & 0.70 & Rampur & 0.42 & 0.75 \\
\hline Bhatpara & 0.27 & 0.47 & Junagadh & 0.45 & 0.65 & Ranchi & 0.27 & 0.53 \\
\hline Bhavnagar & 0.38 & 0.79 & Kadapa & 0.50 & 0.38 & Raurkela & 0.33 & 0.39 \\
\hline Bhilai Nagar & 0.20 & 0.27 & Kakinada & 0.38 & 0.44 & Rohtak & 0.45 & 0.57 \\
\hline Bhilwara & 0.36 & 0.42 & $\begin{array}{l}\text { Kalyan- } \\
\text { Dombivli }\end{array}$ & 0.32 & 0.35 & Saharanpur & 0.47 & 0.61 \\
\hline $\begin{array}{l}\text { Bhiwandi } \\
\text { Nizampur }\end{array}$ & 0.50 & 0.68 & Kamarhati & 0.32 & 0.61 & Salem & 0.38 & 0.66 \\
\hline Bhopal & 0.26 & 0.47 & Kanpur & 0.28 & 0.54 & Sangli Miraj Kupwad & 0.31 & 0.44 \\
\hline Bhubaneswar & 0.26 & 0.47 & Kochi & 0.30 & 0.38 & Shahjahanpur & 0.24 & 0.57 \\
\hline Bijapur & 0.31 & 0.53 & Kolhapur & 0.38 & 0.39 & Shimoga & 0.24 & 0.39 \\
\hline Bikaner & 0.37 & 0.70 & Kolkata & 0.37 & 0.67 & Siliguri & 0.30 & 0.52 \\
\hline Bilaspur & 0.35 & 0.36 & Kollam & 0.26 & 0.38 & Solapur & 0.37 & 0.49 \\
\hline $\begin{array}{l}\text { Bokaro Steel } \\
\text { City }\end{array}$ & 0.00 & 0.45 & Korba & 0.20 & 0.27 & South DumDum & 0.39 & 0.49 \\
\hline Brahmapur & 0.27 & 0.55 & Kota & 0.27 & 0.40 & Srinagar & 0.54 & 0.91 \\
\hline Chandigarh & 0.28 & 0.43 & Kozhikode & 0.25 & 0.39 & Surat & 0.31 & 0.65 \\
\hline Chandrapur & 0.26 & 0.26 & Kulti & 0.31 & 0.52 & Thane & 0.28 & 0.42 \\
\hline Chennai & 0.33 & 0.56 & Kurnool & 0.33 & 0.37 & Thiruvananthapuram & 0.26 & 0.37 \\
\hline Coimbatore & 0.38 & 0.64 & Latur & 0.33 & 0.44 & Thrissur & 0.23 & 0.39 \\
\hline Cuttack & 0.27 & 0.55 & Loni & 0.36 & 0.44 & Tiruchirappalli & 0.34 & 0.54 \\
\hline Davanagere & 0.34 & 0.34 & Lucknow & 0.22 & 0.46 & Tirunelveli & 0.38 & 0.66 \\
\hline Dehradun & 0.30 & 0.44 & Ludhiana & 0.29 & 0.53 & Tiruppur & 0.43 & 0.59 \\
\hline Dhanbad & 0.26 & 0.48 & Madurai & 0.47 & 0.64 & Tumkur & 0.23 & 0.36 \\
\hline Dhule & 0.45 & 0.54 & Maheshtala & 0.48 & 0.62 & Udaipur & 0.28 & 0.43 \\
\hline DMC & 0.33 & 0.54 & Malegaon & 0.69 & 0.76 & Ujjain & 0.33 & 0.48 \\
\hline Durgapur & 0.27 & 0.54 & Mangalore & 0.27 & 0.48 & Ulhasnagar & 0.39 & 0.49 \\
\hline Faridabad & 0.23 & 0.56 & Mathura & 0.36 & 0.63 & Vadodara & 0.14 & 0.60 \\
\hline Firozabad & 0.50 & 0.69 & Meerut & 0.45 & 0.64 & Varanasi & 0.35 & 0.65 \\
\hline Gaya & 0.37 & 0.63 & $\begin{array}{l}\text { Mira- } \\
\text { Bhayandar }\end{array}$ & 0.31 & 0.51 & Vasai-Virar City & 0.27 & 0.47 \\
\hline Ghaziabad & 0.38 & 0.52 & Moradabad & 0.47 & 0.63 & Vijayawada & 0.33 & 0.43 \\
\hline GHMC & 0.25 & 0.52 & Muzaffarnagar & 0.41 & 0.60 & Warangal & 0.21 & 0.63 \\
\hline
\end{tabular}



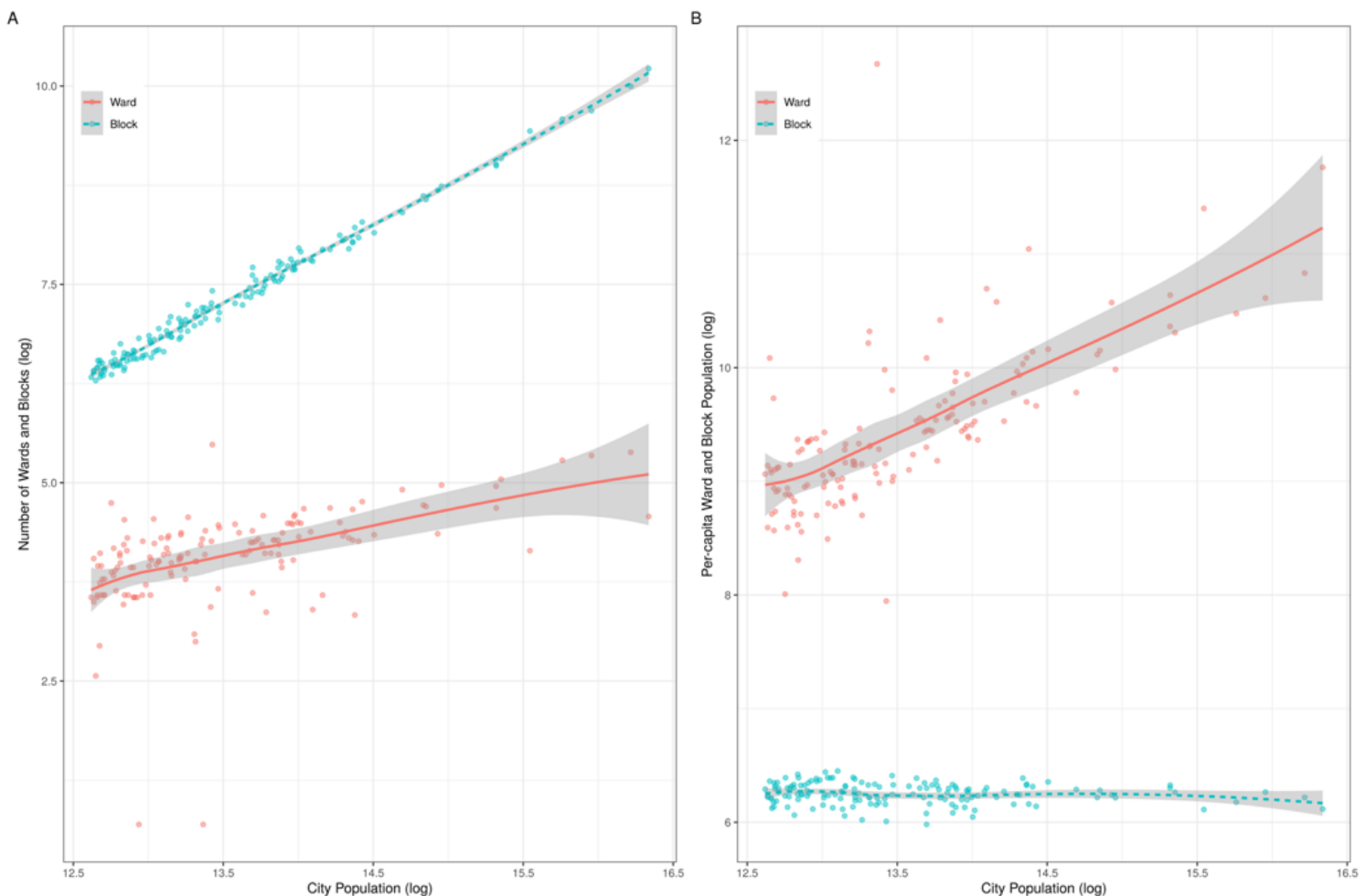

Figure A1: Ward and Block Sizes. Data from Census of India (2011)
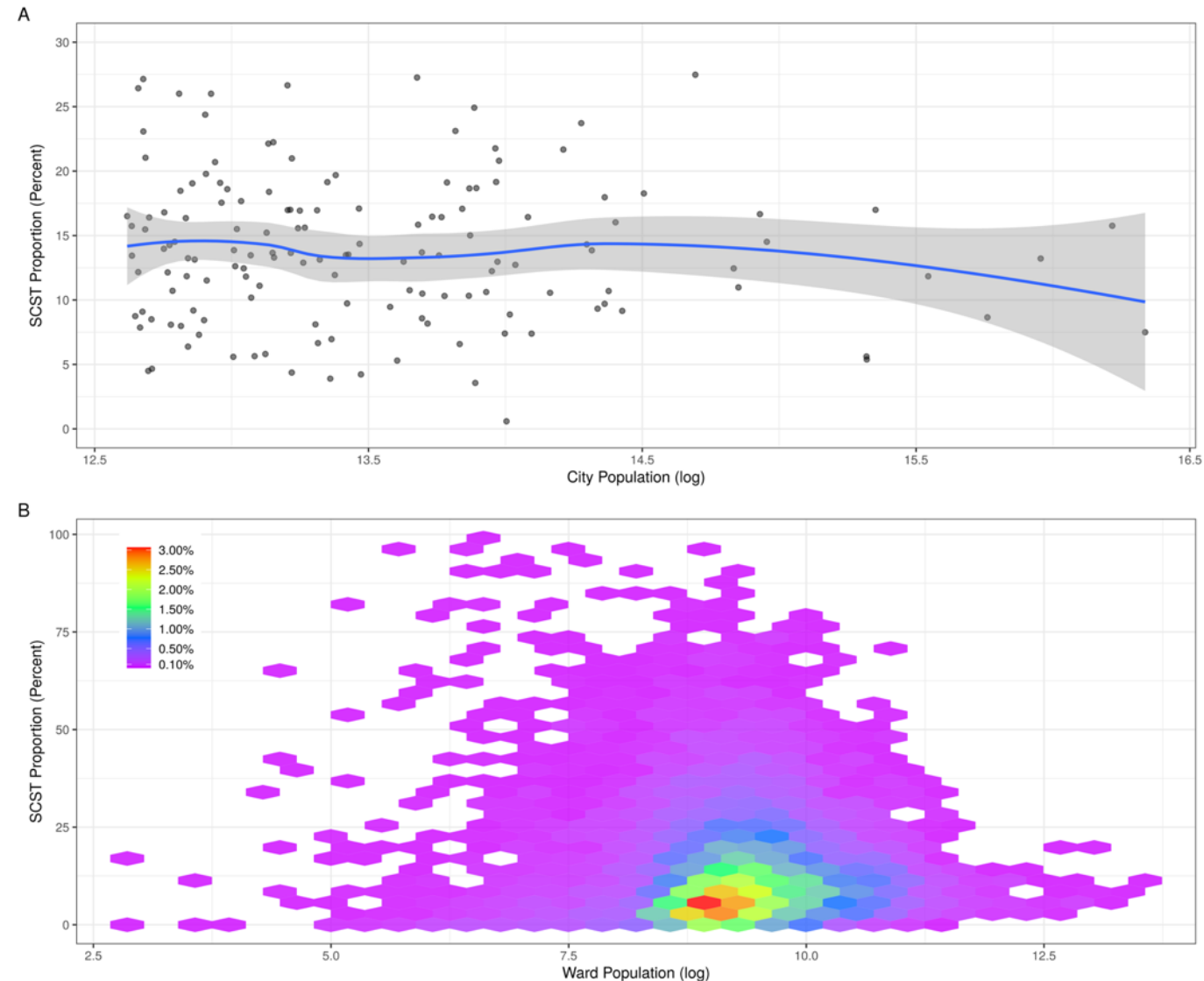

Figure A2: Proportion of Marginalized Groups (SCST). City-wide Proportions (Panel-A) and Ward Proportions (Panel-B). The ward proportion chart is a "binned" graph, and percent cases are shown. Data from Census of India (2011) 